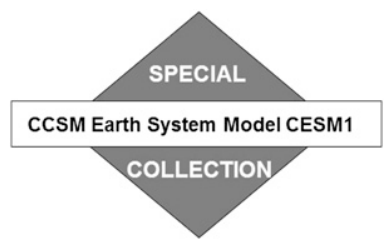

\title{
Climate Change from 1850 to 2005 Simulated in CESM1(WACCM)
}

\author{
Daniel R. Marsh, Michael J. Mills, Douglas E. Kinnison, and Jean-Francois Lamarque \\ National Center for Atmospheric Research,* Boulder, Colorado
}

NATALia CALVO

Universidad Complutense de Madrid, Madrid, Spain

LORENZO M. POLVANI

Columbia University, New York, New York

(Manuscript received 31 July 2012, in final form 5 February 2013)

\begin{abstract}
The NCAR Community Earth System Model (CESM) now includes an atmospheric component that extends in altitude to the lower thermosphere. This atmospheric model, known as the Whole Atmosphere Community Climate Model (WACCM), includes fully interactive chemistry, allowing, for example, a self-consistent representation of the development and recovery of the stratospheric ozone hole and its effect on the troposphere. This paper focuses on analysis of an ensemble of transient simulations using CESM1(WACCM), covering the period from the preindustrial era to present day, conducted as part of phase 5 of the Coupled Model Intercomparison Project. Variability in the stratosphere, such as that associated with stratospheric sudden warmings and the development of the ozone hole, is in good agreement with observations. The signals of these phenomena propagate into the troposphere, influencing near-surface winds, precipitation rates, and the extent of sea ice. In comparison of tropospheric climate change predictions with those from a version of CESM that does not fully resolve the stratosphere, the global-mean temperature trends are indistinguishable. However, systematic differences do exist in other climate variables, particularly in the extratropics. The magnitude of the difference can be as large as the climate change response itself. This indicates that the representation of stratospheretroposphere coupling could be a major source of uncertainty in climate change projections in CESM.
\end{abstract}

\section{Introduction}

One of the enhancements in the first version of the Community Earth System Model (CESM1) relative to the Community Climate System Model (CCSM4) (Gent et al. 2011), upon which it is based, is the inclusion of a "high top" atmosphere model that extends in altitude to the lower thermosphere and includes fully interactive chemistry. The model is the Whole Atmosphere Community Climate Model (WACCM), which has been used

\footnotetext{
* The National Center for Atmospheric Research is sponsored by the National Science Foundation.
}

Corresponding author address: Daniel R. Marsh, Atmospheric Chemistry Division, National Center for Atmospheric Research, P.O. Box 3000, Boulder, CO 80307-3000.

E-mail: marsh@ucar.edu independently to study variability in dynamics and the distribution of minor species in the stratosphere and mesosphere. Prior studies with WACCM include trends resulting from increasing greenhouse gases (e.g., Garcia et al. 2007), the response of the atmosphere to the solar cycle and the flux of energetic particles (e.g., Marsh et al. 2007; Matthes et al. 2010; Jackman et al. 2009), the development and recovery of the ozone hole (Eyring et al. 2007, 2010a), the response of the stratosphere to El NiñoSouthern Oscillation (ENSO) (Sassi et al. 2004; Calvo et al. 2010), and geoengineering (Tilmes et al. 2008). These studies have typically used specified sea surface temperatures (SST) or, in a few cases, a slab ocean model. Inclusion of WACCM as the atmospheric component of CESM, designated CESM1(WACCM), allows for simulation of the past and future climate that attempts to capture coupling processes between the middle and upper atmosphere, troposphere, cryosphere, and ocean. 
It is becoming increasingly recognized that resolving the stratosphere and modeling its variability are necessary to correctly simulate tropospheric weather and climate. Gerber et al. (2012) present an overview of recent research and current understanding of the two-way coupling of the stratosphere to other components in the earth system. Perhaps the clearest example of this is the change in the tropospheric jet stream associated with the development of the Antarctic ozone hole. Recognition of the importance of stratosphere-troposphere coupling has likely led to a large increase in the number of high-top models considered in phase 5 of the Coupled Model Intercomparison Project (CMIP5) (Taylor et al. 2012). Fifteen models with a top above $1 \mathrm{hPa}$, including CESM1 (WACCM), are participating in CMIP5-a threefold increase from the previous assessment (Charlton-Perez et al. 2013).

The primary purpose of this paper is to describe CESM1(WACCM) and the preindustrial and historical simulations conducted as part of CMIP5. The focus here is on the changing climate in CESM1(WACCM) from the preindustrial era to the present day, herein considered to be the period from 1850 to 2005 . As in other papers for the CCSM4 and CESM special collection issues of Journal of Climate, this is intended to provide a baseline characterization of the model rather than a detailed analysis of the mechanisms responsible for particular model characteristics. In addition, we compare the climate, and how it changes over time, to observations and simulations using nearly identical forcing with CCSM4, also conducted as part of CMIP5. How the models and forcings differ is described in the next section. Overall, the model climatologies and also the predicted change in climate are similar. However, we do find systematic differences between the models, particularly in polar regions, that most likely originate in the stratosphere. Characterizing these differences is the aim of the latter part of the paper.

\section{Model description}

For the CMIP5 simulations CESM1(WACCM) includes the active ocean and sea ice components described in Holland et al. (2012) and Danabasoglu et al. (2012). The nominal latitude-longitude resolution of the ocean and sea ice components is $1^{\circ}$, the same as in CCSM4 simulations for CMIP5. The atmosphere is version 4 of WACCM, which is a superset of the Community Atmospheric Model version 4 (CAM4), and includes all of the physical parameterizations of that model (Neale et al. 2013). WACCM is a "high top" chemistry-climate model that extends from the surface to $5.1 \times 10^{-6} \mathrm{hPa}$ (approximately $140 \mathrm{~km}$ ). It has 66 vertical levels and horizontal resolution of $1.9^{\circ}$ latitude by $2.5^{\circ}$ longitude. Notable improvements over version 3, described in Garcia et al. (2007), include an updated parameterization of nonorographic gravity waves generated by frontal systems and convection and a surface stress due to unresolved topography (Richter et al. 2010). The latter, termed turbulent mountain stress (TMS), led to a dramatic improvement in the frequency of Northern Hemisphere (NH) stratospheric sudden warmings (SSWs) in uncoupled simulations (Richter et al. 2010). It will be shown in section 3 that the same improvement is present in CESM1 (WACCM). The model also now includes a representation of the quasi-biennial oscillation (QBO), achieved by relaxing equatorial zonal winds between 86 and $4 \mathrm{hPa}$ to observed interannual variability. The approach is the same as Matthes et al. (2010), except that the QBO phase varies in time with an approximate 28-month period, rather than fixed in either the eastward or westward phase. The inclusion of a QBO leads to a significant improvement in the representation of ozone variability in the tropical stratosphere compared to observations. However, by relaxing to observations there is the potential that trends in the region of relaxation will be damped and so should be treated with caution.

In the coupled simulations presented here the atmospheric component is essentially the same as that used in the specified SST simulations used in the Chemistry-Climate Model Validation 2 (CCMVal2) project (Morgenstern et al. 2010; Richter et al. 2010). The model's chemistry module is based on version 3 of the Model for Ozone and Related Chemical Tracers (Kinnison et al. 2007). The species included within this module are contained within the $\mathrm{O}_{x}, \mathrm{NO}_{x}, \mathrm{HO}_{x}, \mathrm{ClO}_{x}$, and $\mathrm{BrO}_{x}$ chemical families, along with $\mathrm{CH}_{4}$ and its degradation products (a total of 59 species and 217 gasphase chemical reactions). Rate constants are based on Sander et al. (2006). In addition, there are 17 heterogeneous reactions on three aerosol types: nitric acid trihydrate, supercooled ternary solution, and water ice. This version of WACCM does not include a detailed representation of tropospheric chemistry beyond methane and $\mathrm{CO}$ oxidation.

Heating from stratospheric volcanic aerosols is included in the same way as simulations for CCMVal2 and follows Tilmes et al. (2009). In brief, volcanic aerosol surface area density (SAD) is prescribed from a monthly zonal-mean time series derived from observations and is identical to that used in the CCMVal2 REF-B1 simulations (Eyring et al. 2010b). SAD is specified in WACCM, rather than aerosol mass as in CCSM4, since SAD is also used in the calculation of heterogeneous chemistry and plays an important role in the activation of chlorine and 
bromine in the lower polar stratosphere. To calculate heating rates, a volume density of $\mathrm{H}_{2} \mathrm{SO}_{4} / \mathrm{H}_{2} \mathrm{O}$ aerosol is first calculated from SAD by assuming a lognormal size distribution with fixed width and number density (Kinnison et al. 2007). The mass of $\mathrm{H}_{2} \mathrm{SO}_{4}$ per unit volume can then be derived given the ratio of $\mathrm{H}_{2} \mathrm{O}$ to $\mathrm{H}_{2} \mathrm{SO}_{4}$ within each aerosol droplet as parameterized by Tabazadeh et al. (1997). In contrast, this $\mathrm{H}_{2} \mathrm{SO}_{4}$ mass is supplied in CCSM4 using the dataset of Ammann (2003). Independent of how the $\mathrm{H}_{2} \mathrm{SO}_{4}$ aerosol mass is calculated, it is handled by the radiative transfer code [Community Atmosphere Model Radiative Transfer (CAMRT)] in the same manner when calculating heating rates. In these calculations it is assumed volcanic aerosol mass has a fixed lognormal distribution with width of the distribution equal to $1.25 \mu \mathrm{m}$ and a geometric mean radius of $0.5 \mu \mathrm{m}$.

WACCM includes the following major volcanic eruptions in historical simulations: Krakatau (1883), Santa Maria (1902), Agung (1963), El Chichón (1982), and Mount Pinatubo (1991). The specification of SAD for Krakatau and Santa Maria are identical to that of Pinatubo since no SAD observations are available for those eruptions. The effects of smaller volcanic eruptions [e.g., Fernandina (1968) and Fuego (1974)] were not included in the WACCM historical simulations. The optical depths for scattering and absorption by volcanic aerosol in WACCM typically agree to within a factor of 2 with those in CCSM4. For example, the globally averaged optical depth in the spectral range between 0.35 and $0.64 \mu \mathrm{m}$ (roughly corresponding to the visible spectrum) for the 18-month period following Pinatubo was 0.15 in WACCM and 0.12 in CCSM4. For El Chichón it was 0.04 in WACCM and 0.07 in CCSM4.

WACCM explicitly represents the radiative transfer of carbon dioxide $\left(\mathrm{CO}_{2}\right)$, methane $\left(\mathrm{CH}_{4}\right)$, nitrous oxide $\left(\mathrm{N}_{2} \mathrm{O}\right)$, and two halogens: CFC- $11^{*}$ and CFC-12. The abundance of CFC-11* not only contains the contribution of the chlorofluorocarbon CFC-11, but also the remaining halogens not explicitly represented as radiatively active gases within the radiative transfer code but which are calculated by the model chemistry (i.e., $\mathrm{CCl}_{4}, \mathrm{CH}_{3} \mathrm{CCl}_{3}$, CFC-113, HCFC-22, Halon-1211, and Halon-1301). The CFC-11* is calculated as the weighted sum of these species, where the weights are the ratio of the radiative efficiency $\left(\mathrm{W} \mathrm{m}^{-2} \mathrm{ppb}^{-1}\right)$ of each species relative to CFC-11. Radiative efficiencies are those in Table 2.14 of Forster et al. (2007).

Solar spectral irradiance is specified from the model of Lean et al. (2005) rather than the parameterized fluxes used in version 3 (Marsh et al. 2007). All irradiances have been scaled by 0.9965 following the recommendation of the Stratospheric Processes and Their Role in
Climate (SPARC)-SOLARIS group (http://sparcsolaris. geomar.de/). This scaling reflects a new, lower, estimate of total solar irradiance (TSI) made by the Total Irradiance Monitor on the National Aeronautics and Space Administration Earth Observing System Solar Radiation and Climate Experiment (Kopp and Lean 2011). They report a TSI of $1360 \pm 0.5 \mathrm{~W} \mathrm{~m}^{-2}$ for the solar minimum in 2008. Spectral irradiances are input not only to the radiative transfer calculations but also are used to compute photolysis rates in the chemistry module. Heating rates vary as the irradiance varies in each spectral band, unlike in CAM4, where heating in all bands are scaled uniformly with the variation in TSI.

CCSM4 used for CMIP5 simulations differs in that its radiatively active gas concentrations are specified, it does not include a QBO or nonorographically generated gravity waves, and does not have TMS active. CCSM4 has 26 vertical levels and its model top is at $3.54 \mathrm{hPa}$ (approximately $40 \mathrm{~km}$ ). The 18 pressure levels between the surface and $100 \mathrm{hPa}$ are identical in WACCM and CCSM4. WACCM has higher vertical resolution between $100 \mathrm{hPa}$ and the top level in CCSM4 (17 levels in WACCM versus 8 in CCSM4). CCSM4 horizontal resolution is $0.95^{\circ}$ latitude by $1.25^{\circ}$ longitude. The absence of TMS and the differing horizontal resolution makes it difficult to determine if simulation differences are due to these model features or to the vertical extension of the model into the thermosphere and inclusion of interactive chemistry. We have therefore conducted a limited set of simulations with CCSM4 at the WACCM horizontal resolution $\left(1.9^{\circ} \times 2.5^{\circ}\right)$ and with TMS turned on. This model configuration we term CCSM4-WSET, for CCSM4 with WACCM settings, which nevertheless has the same "low top" and specified chemistry as CCSM4. For the sake of brevity, in the remainder of the paper we refer to CESM1(WACCM) simply as WACCM, and, unless otherwise denoted, CCSM4 refers to the model with $0.95^{\circ} \times 1.25^{\circ}$ horizontal resolution. The various model names and their configurations are listed in Table 1. In all model configurations used in this study the ocean and sea ice components are configured identically (including model resolution) as in Meehl et al. (2012).

The majority of simulations presented here were performed on the National Center for Atmospheric Research IBM "bluefire" supercomputer. Utilizing 192 POWER6 processors the model is capable of generating approximately 4.5 simulation years per day. In comparison, CCSM4 running on 256 processors generates $\sim 9.3$ simulation years per day, and CCSM4-WSET running on 128 processors generates $\sim 15.5$ simulation years per day. In other words, the computational cost of running WACCM is 1.6 times that of CCSM4 and 5.2 times that of CCSM4-WSET. 
TABLE 1. Summary of model configurations used in this study.

\begin{tabular}{lcccccc}
\hline \hline \multicolumn{1}{c}{ Model name } & Horizontal resolution & Model top $(\mathrm{hPa})$ & Number of levels & TMS & QBO & Interactive chemistry \\
\hline WACCM & $1.9^{\circ} \times 2.5^{\circ}$ & $5.96 \times 10^{-6}$ & 66 & On & Yes & Yes \\
WACCM NO-TMS & $1.9^{\circ} \times 2.5^{\circ}$ & $5.96 \times 10^{-6}$ & 66 & Off & Yes & Yes \\
CCSM4 & $0.95^{\circ} \times 1.25^{\circ}$ & 3.54 & 26 & Off & No & No \\
CCSM4-WSET & $1.9^{\circ} \times 2.5^{\circ}$ & 3.54 & 26 & On & No & No \\
\hline
\end{tabular}

\section{Description of simulations}

An ensemble of three WACCM simulations was performed with all observed forcing from 1955 to 2005. The observed forcing included changes in surface concentrations of radiatively active species, daily solar spectral irradiance, volcanic sulfate heating, and the QBO. These simulations have been designated runs 002, 003, and 004 . We list the run designations used for WACCM and CCSM4, as has been done in other papers within the CCSM4 and CESM special collection issues, to allow correct identification of the simulations used. The increased computational cost of WACCM meant that it was impractical to run the full historical period for all ensemble members. Therefore, initial conditions for 1955 for all model components were taken from a single historical simulation (1850-2005) that started from year 156 of a WACCM perpetual preindustrial (1850) conditions simulation. This preindustrial simulation, designated 006 , was continued for a further 140 years to ensure that there were no large drifts in the constant preindustrial forcing simulation. Historical surface concentrations of greenhouse gases were taken from Meinshausen et al. (2011). Table 2 lists the annual-mean surface volume mixing ratios for the radiatively active gases $\mathrm{CO}_{2}, \mathrm{CH}_{4}, \mathrm{~N}_{2} \mathrm{O}$, and two chlorofluorocarbons (CFC-11 and CFC-12). Between 1850 and 2005, $\mathrm{CO}_{2}$ increased $33 \%, \mathrm{CH}_{4} 121 \%$, and $\mathrm{N}_{2} \mathrm{O} 16 \%$. Concentration of the anthropogenic chlorofluorocarbons CFC-11 and CFC-12 are essentially zero before 1960 but increase rapidly over the following 45 years. A single 1955-2005 WACCM simulation was also performed in which the TMS parameterization did not operate (WACCM NO-TMS), along with a 3-member ensemble of 1955-2005 CCSM4-WSET simulations (runs 004, 005, and 006). The historical simulations of CCSM4 that are compared to WACCM are described in Meehl et al. (2012). We make use of simulations 005-009, 011, and 012 in our comparisons.

\section{Model climatology}

\section{a. Surface climate}

We first present a brief summary of surface climate variables for preindustrial conditions along with a comparison of those from CCSM4. Averaged over the last
200 years of the preindustrial simulation (from years 96 to 295), WACCM global annual-mean surface temperature is $287.6 \pm 0.2 \mathrm{~K}$. The top of the atmosphere net radiative flux (net shortwave minus net longwave flux, positive downward) was $-0.0003 \mathrm{~W} \mathrm{~m}^{-2}$, indicating the atmosphere is in radiative equilibrium. In comparison, the CCSM4 global-mean surface temperature calculated from year 800 to 999 of preindustrial run 006 is $287.2 \pm$ $0.2 \mathrm{~K}$ and a net radiative flux of $-0.102 \mathrm{~W} \mathrm{~m}^{-2}$. The annual mean temperatures are summarized in Table 3 , along with the mean temperature over three latitude bands of approximately equal area. It is clear from these averages that almost all of the difference between WACCM and CCSM4 global-mean temperatures is due to the difference in temperature south of $20^{\circ} \mathrm{S}$ where WACCM is $0.9 \mathrm{~K}$ warmer. The primary cause of this difference is related to sea ice extent (SIE, defined as the total area of all grid boxes with an ice coverage by area greater than $15 \%)$. SIE in CCSM4 is $3.9 \times 10^{-6} \mathrm{~km}^{2}$ $(24 \%)$ greater than the SIE in WACCM. Since surface temperature over sea ice is colder than over the ocean, this leads to a colder mean temperature.

Sea level pressure (SLP) is significantly different between WACCM and CCSM4 in the tropical and NH latitude bands. Over the pole wintertime SLP can be as much as $12 \mathrm{hPa}$ larger in WACCM than CCSM4 (not shown). In this regard, the SLP bias relative to observations in WACCM is likely less than in CCSM4: de Boer et al. (2012) demonstrated a 6-13-hPa negative bias in CCSM4 in March and April SLP relative to the 40-yr European Centre for Medium-Range Weather Forecasts Re-Analysis (ERA-40). Precipitation rates also appear to be significantly different between WACCM and CCSM4

TABLE 2. Global-mean annual-mean surface volume mixing ratios of constituents specified at the lower boundary of the model. Units are parts per million (ppm), parts per billion (ppb), or parts per trillion (ppt).

\begin{tabular}{lrrrr}
\hline \hline & 1850 & 1960 & 1985 & 2005 \\
\hline $\mathrm{CO}_{2}(\mathrm{ppm})$ & 285 & 316 & 345 & 379 \\
$\mathrm{CH}_{4}(\mathrm{ppb})$ & 787 & 1241 & 1630 & 1746 \\
$\mathrm{~N}_{2} \mathrm{O}(\mathrm{ppb})$ & 275 & 291 & 305 & 319 \\
$\mathrm{CFC}-11(\mathrm{ppt})$ & 0 & 9 & 203 & 254 \\
$\mathrm{CFC}-12(\mathrm{ppt})$ & 0 & 28 & 372 & 539 \\
\hline
\end{tabular}


TABLE 3. WACCM and CCSM4 annual-mean temperature $T$, land temperature, SST, SLP, precipitation $P$, and SIE for preindustrial conditions. A grid box must be covered by at least $90 \%$ land or sea to be included in those averages. Means are calculated over $200-\mathrm{yr}$ periods under constant 1850 conditions. The $2 \sigma$ uncertainties on the sample mean are listed.

\begin{tabular}{llcccccc}
\hline \hline & Model & $T(\mathrm{~K})$ & $T$ land $(\mathrm{K})$ & SST $\left({ }^{\circ} \mathrm{C}\right)$ & SLP $(\mathrm{hPa})$ & $P\left(\mathrm{~mm} \mathrm{day}^{-1}\right)$ & ${\mathrm{SIE}\left(10^{6} \mathrm{~km}^{2}\right)}^{2}$ \\
\hline Global & WACCM & $287.6 \pm 0.2$ & $280.5 \pm 0.4$ & $20.3 \pm 0.2$ & $1011.3 \pm 0.0$ & $2.83 \pm 0.03$ & $30.4 \pm 0.5$ \\
& CCSM4 & $287.2 \pm 0.2$ & $280.1 \pm 0.4$ & $20.4 \pm 0.2$ & $1011.2 \pm 0.0$ & $2.93 \pm 0.02$ & $33.6 \pm 0.6$ \\
$21^{\circ}-90^{\circ} \mathrm{N}$ & WACCM & $281.7 \pm 0.3$ & $278.6 \pm 0.4$ & $17.6 \pm 0.2$ & $1016.9 \pm 0.4$ & $2.00 \pm 0.04$ & $14.0 \pm 0.3$ \\
& CCSM4 & $281.6 \pm 0.3$ & $277.7 \pm 0.4$ & $17.5 \pm 0.2$ & $1014.9 \pm 0.4$ & $2.13 \pm 0.04$ & $13.3 \pm 0.3$ \\
$21^{\circ} \mathrm{S}-21^{\circ} \mathrm{N}$ & WACCM & $299.3 \pm 0.5$ & $297.1 \pm 0.7$ & $26.7 \pm 0.4$ & $1010.6 \pm 0.4$ & $4.10 \pm 0.08$ & - \\
& CCSM4 & $299.3 \pm 0.4$ & $296.6 \pm 0.6$ & $26.9 \pm 0.4$ & $1012.0 \pm 0.4$ & $4.21 \pm 0.08$ & - \\
$21^{\circ}-90^{\circ} \mathrm{S}$ & WACCM & $280.5 \pm 0.2$ & $261.2 \pm 0.6$ & $14.4 \pm 0.1$ & $1006.6 \pm 0.4$ & $2.25 \pm 0.04$ & $16.4 \pm 0.5$ \\
& CCSM4 & $279.6 \pm 0.2$ & $262.2 \pm 0.6$ & $14.3 \pm 0.1$ & $1006.7 \pm 0.4$ & $2.34 \pm 0.04$ & $20.3 \pm 0.5$ \\
\hline
\end{tabular}

with WACCM rates about $0.1 \mathrm{~mm} \mathrm{day}^{-1}$ less across all three latitude bands. However, these differences in SLP and precipitation may have more to do with horizontal resolution, or the addition of TMS, since for the 19862005 period WACCM SLP and precipitation are not significantly different to those in CCSM4-WSET.

\section{b. Middle atmosphere dynamics}

Zonal-mean zonal winds for July averaged across the ensemble and between year 1990 and 1999 are shown in Fig. 1a. The winds are almost identical to those shown in Richter et al. (2010) (Fig. 8d) and show the same biases relative to winds from the Upper Atmosphere Research Satellite Reference Atmosphere Project (URAP) climatology (Swinbank and Ortland 2003) shown in Fig. 1b. This is expected since the atmospheric model is nearly unchanged from the model of Richter et al. (2010). The largest biases in the stratosphere are in the location of the maximum of the $\mathrm{NH}$ easterly jet (too near to the equator) and a Southern Hemisphere ( $\mathrm{SH}$ ) westerly jet that is too strong by almost $30 \mathrm{~m} \mathrm{~s}^{-1}$. Zonal mean winds in January (not shown) are again very similar to those shown in Richter et al. (2010) and agree well with URAP climatology.

Figures $2 \mathrm{a}$ and $2 \mathrm{~b}$ show the WACCM ensemble-mean zonal mean temperatures for January and July from the stratosphere to the lower mesosphere averaged over the years from 2002 to 2005 . For comparison, we show in Figs. $2 \mathrm{c}$ and $2 \mathrm{~d}$ the monthly mean temperature observations over the same period obtained from the Sounding of the Atmosphere using the Broadband Emission Radiometry (SABER) instrument on the Thermosphere, Ionosphere, and Mesosphere Energetics and Dynamics (TIMED) satellite (Remsberg et al. 2008). The model is capable of reproducing height and temperature of the cold summer mesopause. The hemispheric asymmetry in the region of the coldest summer temperatures (i.e., the NH has a larger region of temperatures below $130 \mathrm{~K}$ ), seen in observations, is reproduced in the model. However, it appears that these cold temperatures extend too far equatorward in the model when compared to SABER. Lower in the atmosphere there are no large discrepancies between WACCM and SABER except in the $\mathrm{SH}$ polar stratosphere in July. The region of cold temperatures is too large in the model, extending
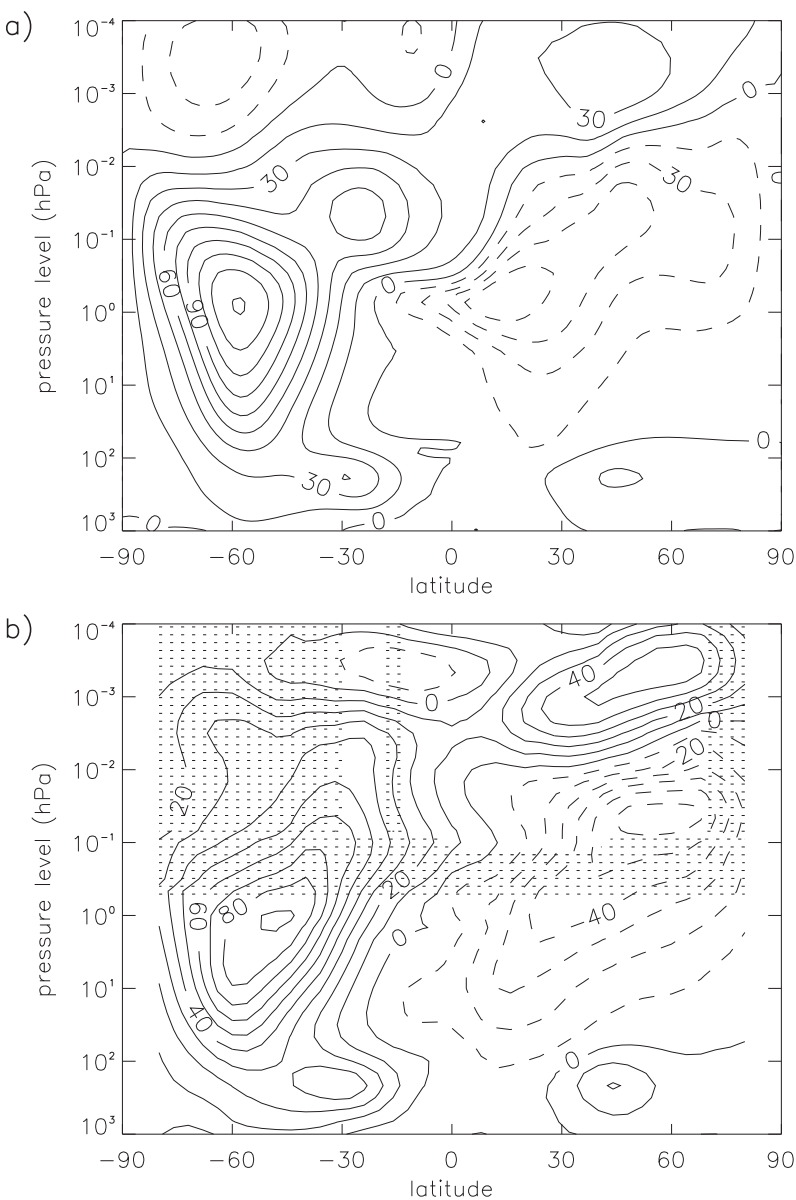

FIG. 1. (a) WACCM zonal-mean zonal winds $\left(\mathrm{m} \mathrm{s}^{-1}\right)$ for July averaged over all ensemble members for the period 1990-99. (b) URAP climatological July zonal-mean zonal winds. Shading in URAP winds indicates regions of insufficient observational coverage. 

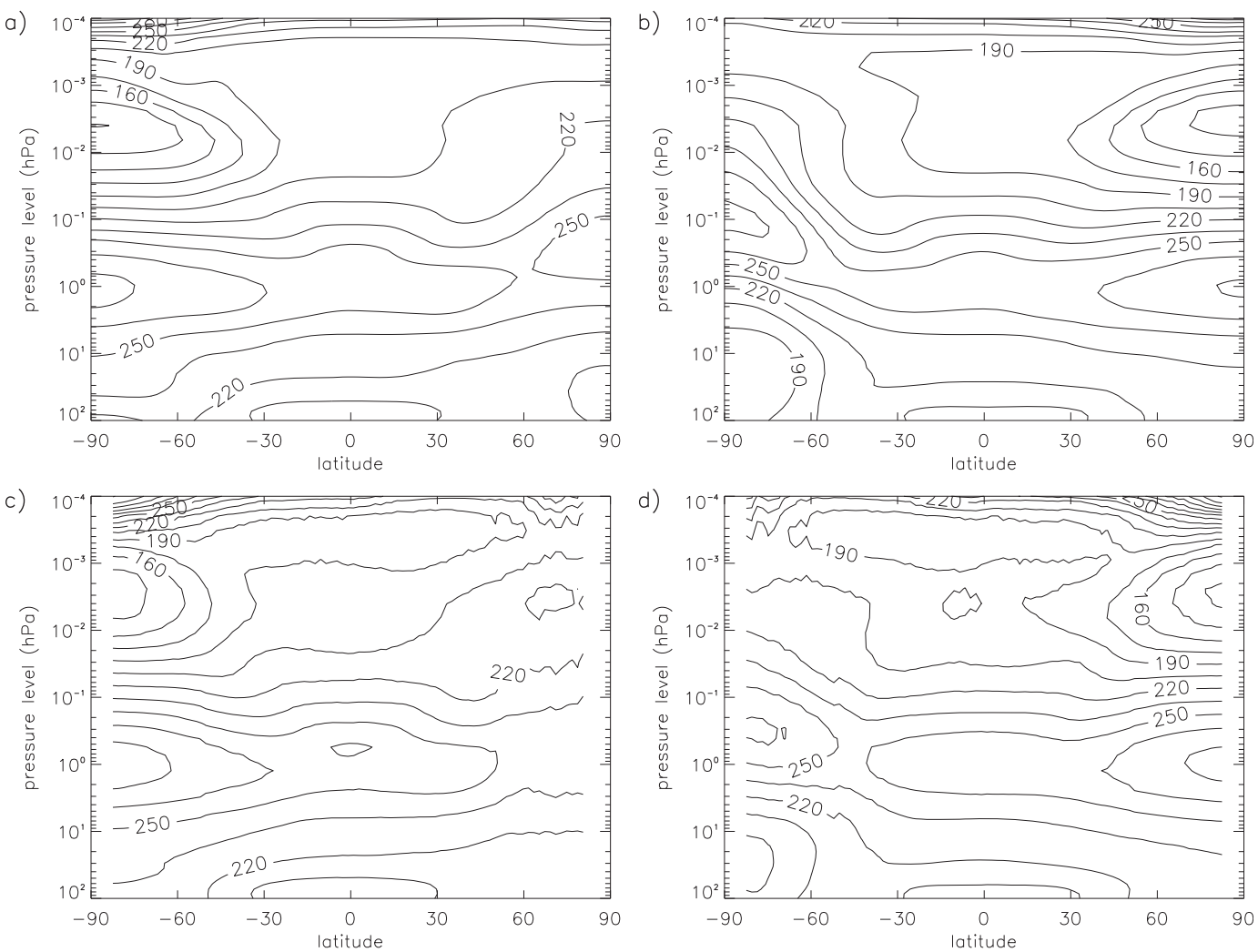

FIG. 2. WACCM zonal-mean monthly-mean temperature (K) for (a) January and (b) July averaged over all ensemble members for the period 2002-05. (c),(d) TIMED/SABER January and July zonal-mean temperature mean for the same period.

throughout the stratosphere and displacing the stratopause upward. This bias is long standing and not unique to WACCM (see, e.g., Boville 1995) and is often termed the "cold pole problem." This bias in temperature and the too strong zonal mean winds shown above could be reduced by increasing nonorographic gravity wave drag, but at the cost of a less realistic mesopause. Development of the gravity wave parameterization is ongoing, with the aim of reducing this bias while maintaining a reasonable thermal structure throughout the entire atmosphere.

\section{c. SSWS}

Stratospheric sudden warmings (SSWs) are the dominant mode of variability in the NH winter stratosphere, and reproducing their frequency is a critical benchmark for any high-top climate model. They consist of a disruption of the normal wintertime state of the extratropical stratospheric circulation, which is typically a strong jet surrounding the pole. The disruption can involve a displacement of the westerly winds away from the pole, or in extreme cases a reversal of the winds in which case it is classified as a major warming. A thorough examination of SSW frequency and type in specified SST WACCM simulations was conducted by de la Torre et al. (2012). For this overview, we focus only on the frequency of major SSWs in the CMIP5 coupled simulations. Detection of major SSWs follows the method described in Charlton and Polvani (2007) and Butler and Polvani (2011), wherein the "central date" of an SSW is the first day in which zonal-mean zonal winds at $10 \mathrm{hPa}, 60^{\circ} \mathrm{N}$ become westward. An SSW is not counted if it occurs within 20 days following a previous SSW or if it is considered a final warming (one in which westerlies are not reestablished for at least 10 days prior to 30 April).

Figure 3a shows the number of SSWs that occurred in the 45 winters between December 1959 and March 2004, as a function of month, for each of the three WACCM ensemble members. For comparison, also shown are the numbers of SSWs from the National Centers for Environmental Prediction (NCEP)-National Center for Atmospheric Research (NCAR) reanalysis dataset that occurred over the same period calculated from the central dates listed by Butler and Polvani (2011). Summed over the winter the frequency of SSWs ranges between 3.3 and 5.3 decade $^{-1}$ with an average of 4.6 decade $^{-1}$. This is slightly lower than the SSW 
a)

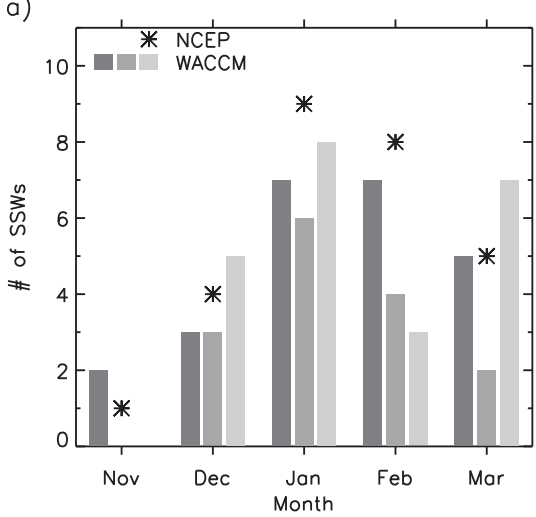

b)

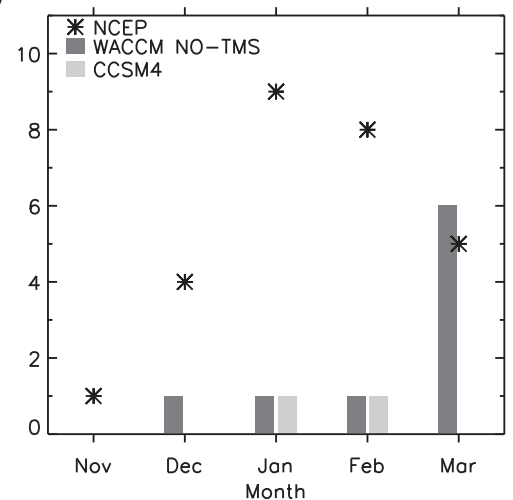

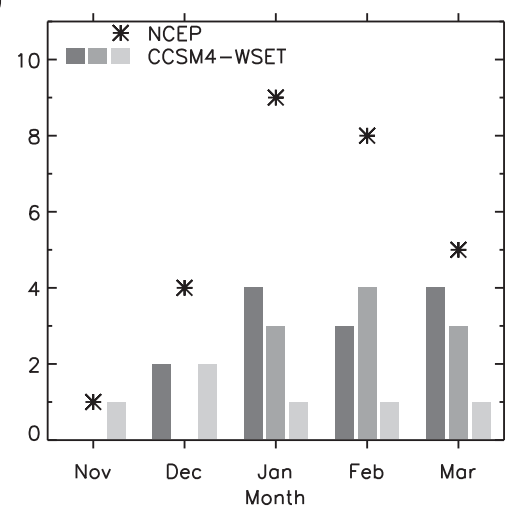

FIG. 3. Number of SSWs by month occurring in simulations covering the period 1960-2004 in (a) an ensemble of three simulations in WACCM, (b) a WACCM simulation without TMS (dark bar) and a CCSM4 simulation (light bar), and (c) an ensemble of three simulations in CCSM4-WSET. Bar shading indicates ensemble member in (a) and (c). SSWs from the NCEP-NCAR reanalysis dataset (19602004) are calculated from central dates listed by Butler and Polvani (2011).

frequency in the NCEP-NCAR reanalysis of 6 decade $^{-1}$. It is possible that the discrepancy is within the natural variability. As noted by de la Torre et al. (2012), the frequency of SSWs depends on the period analyzed; for example, between 1960 and 1989 they found only 4.7 decade $^{-1}$ in the NCEP-NCAR reanalysis dataset. On average WACCM shows the largest number of SSWs in January (seven between 1960 and 2005), with almost five occurring in both February and March and fewer occurring in November (0.7) and December (3.7). The reduced frequency in December relative to January is in agreement with observations and an improvement over the specified SST WACCM simulations reported by de la Torre et al. (2012).

As a point of comparison with a low-top model, the SSWs from a single CCSM4 simulation are shown in Fig. 3b. There were just two SSWs between 1960 and 2005 in this simulation: one occurring in January, the other in February. This indicates a severe lack of internal variability in the $\mathrm{NH}$ winter polar stratosphere in CCSM4. In the same figure the number of SSWs from a WACCM simulation without the turbulent mountain stress parameterization is shown. Over the same period there were just three SSWs between November and February (NDJF). There were six SSWs in March, however, which is comparable to the simulations with TMS. As mentioned above, the dependence of SSWs on the inclusion of TMS was reported by Richter et al. (2010), who show a fourfold reduction in major SSWs during NDJF (from 4 to 1 decade $^{-1}$ when TMS is turned off). The cause of the increase in SSWs with TMS, they suggest, is related to a TMS-induced change in the tropospheric circulation and orographic gravity wave drag, which modifies the upward propagation of stationary planetary waves and the initiation of SSWs. Since this mechanism would also be present in a model with a low top and with orographic gravity waves, such as CCSM4, we calculated the SSW frequency in CCSM4-WSET (shown in Fig. 3c) that does include TMS. The frequency in NDJF is a factor of 4 larger in CCSM4-WSET than in the CCSM4 simulation (1.6 versus 0.4 decade $^{-1}$ ). While this is a dramatic improvement, it is still less than half the frequency found in the ensemble of WACCM simulations, suggesting a fully resolved stratosphere is necessary to obtain a reasonable SSW occurrence frequency.

Closely related to SSWs are variations in the northern annular mode (NAM) index. The NAM index is a measure of the variability of the extratropical circulation, usually calculated as the leading empirical orthogonal function of hemispheric geopotential height (see, e.g., Baldwin and Dunkerton 2001; Baldwin and Thompson 2009; Gerber et al. 2010; Kushner 2010). Anomalies in the NAM are observed to propagate from the stratosphere to the troposphere over several weeks, implying that changes in tropospheric weather can be traced back to changes in the stratosphere. While a detailed analysis of NAM variability in WACCM is beyond the scope of this overview, Fig. 4 presents composites of time-height variations in the NAM for the major SSWs identified in Fig. 3 for WACCM and CCSM4-WSET. The NAM index is calculated using a simplification of the method of Gerber et al. (2010), which involves no EOF computation. Briefly, it is calculated from daily geopotential heights as follows: 1 ) the daily global mean at each level is removed, 2) an area-weighted average is taken over the polar cap $\left.\left(>65^{\circ} \mathrm{N}\right), 3\right)$ the time mean and any linear trend are removed, and 4) the sign is reversed and normalized by the standard deviation at each level.

Figure 4 shows that coincident with a major SSW there is a large negative perturbation in the NAM, as 
a) WACCM

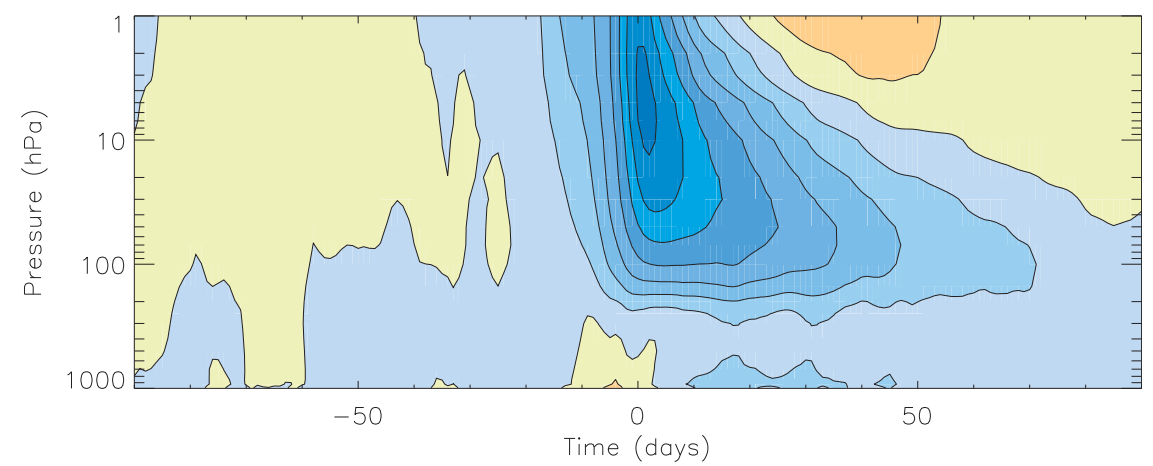

b) CCSM4-WSET

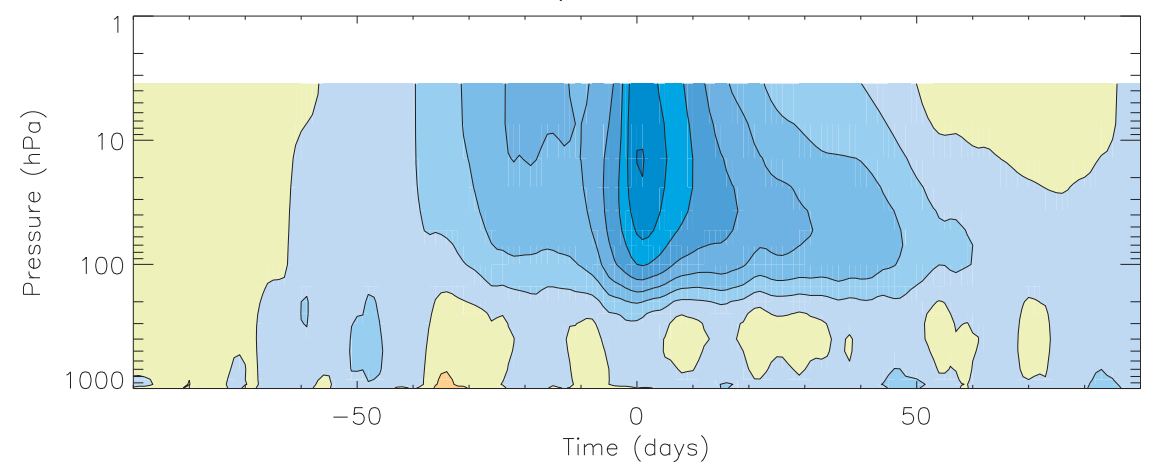

FIG. 4. NAM index composite constructed from winters with major SSWs for the ensemble of (a) WACCM and (b) CCSM4-WSET simulations. Day 0 is the central date of each SSW. Contours every 0.5 . Blue is negative; yellow is positive.

originally reported in Baldwin and Dunkerton (2001). The perturbation appears to extend into the troposphere and persists for more than 50 days in WACCM. The perturbations in CCSM4-WSET do not last as long, particularly in the troposphere where the index changes sign several times after the central date of the SSW. It should be noted that, not only is the propagation of the signal stronger in WACCM than CCSM4-WSET, but also this phenomenon occurs twice as frequently in WACCM and is practically absent in CCSM4 (not shown). These results are consistent with the analysis of Charlton-Perez et al. (2013), who examined differences in the propagation of negative NAM events between eight high-top and six low-top models in CMIP5 simulations. They similarly found that the high-top model composite produced negative NAM events that persisted for approximately 60 days in the lower stratosphere and troposphere, whereas the low-top models response was shorter lived.

\section{d. Atmospheric blocking}

Recent studies have identified a link between SSWs and large-scale quasi-stationary tropospheric disturbances in the troposphere at midlatitudes, such as blocking events (e.g., Martius et al. 2009; Castanheira and Barriopedro 2010). However, modeling of blocking in state-of-the-art coupled climate models is still a challenging task, with most models underestimating blocking frequency (Scaife et al. 2010). Northern Hemisphere blocking frequency in CAM3 and CAM4 was examined by Neale et al. (2013). Analyzing $500-\mathrm{hPa}$ geopotential heights following the technique of D'Andrea et al. (1998), improved agreement was found between the observed blocking frequency from the NASA Modern-Era Retrospective Analysis for Research and Applications (MERRA) (Rienecker et al. 2011) and CAM4 during spring and summer compared to CAM3. We calculated spring and summer WACCM blocking frequency using the same method for each of the three WACCM simulations over the period 19812000. As in the previous analysis by Neale et al. (2013), there is substantial variation in blocking frequency across the ensemble members; however, WACCM maintains the improvement found in CAM4 in blocking frequencies over western Europe compared to CAM3 (not shown) and, similar to CAM4, has a deficit in the occurrence of Atlantic blocking. Summertime Pacific blocking frequency in two of the three WACCM simulations is very close to observed. 


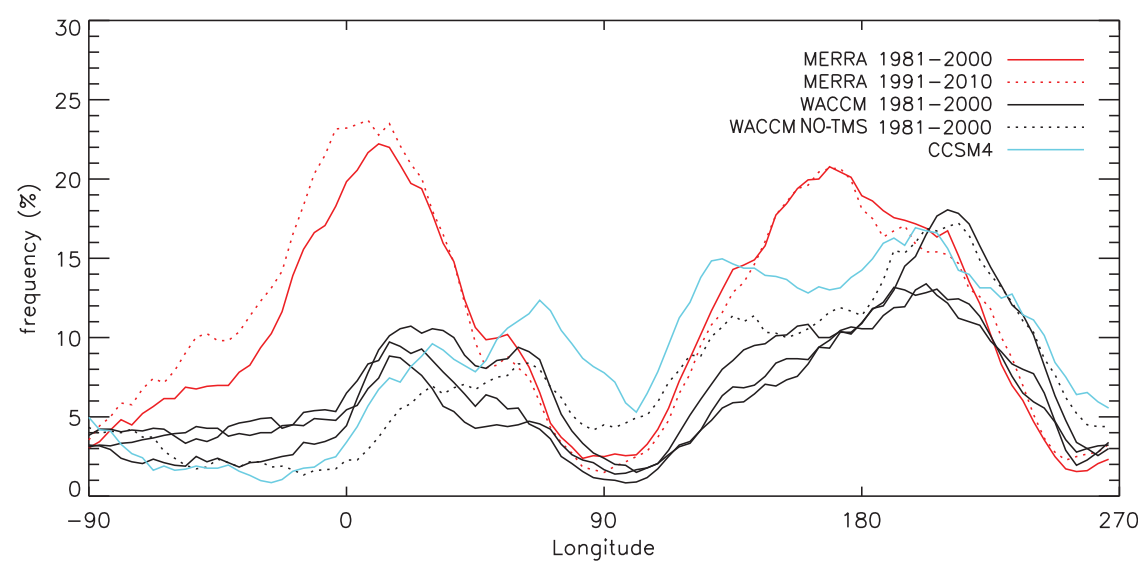

FIG. 5. Blocking frequency in the Northern Hemisphere calculated following D'Andrea et al. (1998) for MERRA reanalysis, CCSM4, and WACCM during December-February.

Since blocking is observed to occur before almost all SSWs (Martius et al. 2009), we additionally analyzed blocking frequency in the $\mathrm{NH}$ winter season between 1981 and 2000 in the three WACCM simulations and a single CCSM4 simulation (shown in Fig. 5). It is clear that both WACCM and CCSM4 fail to reproduce the frequency of blocks in both the Atlantic and western European sectors. There does not appear to be a discernible difference in the frequency in these sectors between CCSM4 and WACCM. This is notable since the frequency of SSWs in these models is drastically different. Also shown in Fig. 5 is the blocking frequency of the single WACCM simulation conducted without TMS. While the frequency over Europe in this simulation is about half of the other WACCM simulations, it is doubtful this difference can be attributed to the absence of TMS in the model (in particular because the CCSM4 simulation without TMS shows a blocking frequency comparable to the WACCM simulations with TMS). It therefore seems unlikely that the mechanism by which TMS drives the large differences in SSWs is through its effect on blocking, as diagnosed using the method of D'Andrea et al. (1998). A detailed analysis of the blocking/ SSW relationship in WACCM and CCSM4 will be performed in a future study.

\section{e. ENSO}

ENSO is one of the main sources of interannual climate variability, and its simulation in CCSM4 has been evaluated by Deser et al. (2012). In this overview, we focus on comparing just one aspect of the ENSO in WACCM: the variability in the Niño-3.4 SST index (N3.4: the standardized mean sea surface temperature in the region $5^{\circ} \mathrm{S}-5^{\circ} \mathrm{N}, 120^{\circ}-170^{\circ} \mathrm{W}$ ). The detrended $\mathrm{N} 3.4$ time series for each WACCM ensemble member is shown in Fig. 6a, along with the Hadley Centre Sea Ice and Sea
Surface Temperature dataset (HadISST) observations (Rayner et al. 2003). Inspection of the time series suggests that the periodicity in the N3.4 index in the model is similar to the observed one, but the amplitude of the signal is somewhat larger. To verify this we calculated the power spectra of N3.4 from the detrended observations and WACCM simulations. The power spectrum for WACCM is calculated as the average of the spectra from each simulation and is shown in Fig. 6b. The peak amplitude of N3.4 in WACCM falls within the 3-5-yr period and is approximately twice that of the observed amplitude. There is also an indication that the power spectrum has two peaks, which are also seen in the observations. The WACCM power spectrum is very similar to that calculated from the CCSM4 simulations [dotted line in Fig. 6b, taken from Deser et al. (2012)]. This is somewhat surprising since Deser et al. reported that the amplitude of N3.4 in CCSM4 $2^{\circ}$ simulations is considerably larger. Clearly, the horizontal resolution of the atmospheric model is not the only factor determining N3.4 amplitude. To explore this further, we calculated the CCSM4-WSET N3.4 index power spectrum (also shown in Fig. 6b) and found its amplitude and period comparable to that of the WACCM and CCSM4 simulations, even though it is at $2^{\circ}$ resolution. The reason for the difference is difficult to discern but may again be related to the inclusion of TMS in the CCSM4-WSET model.

\section{Climate change $1850-2005$}

\section{a. Surface climate}

Over the majority of the globe there has been a statistically significant increase in WACCM surface temperature between the preindustrial era and the ensemble average taken over the last 20 years of the historical simulations. Generally, temperature increases are largest 


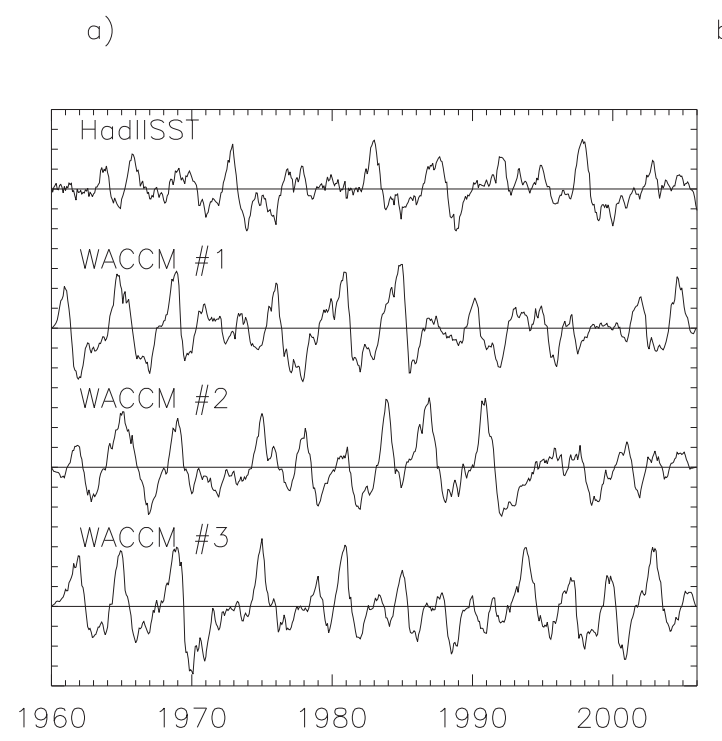

b)

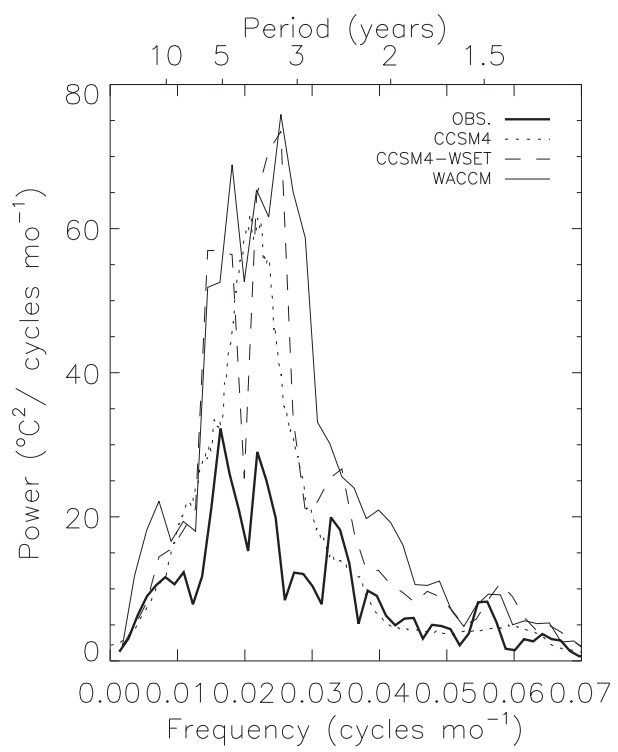

FIG. 6. (a) The detrended N3.4 time series from observations (HadISST, top) and an ensemble of three WACCM simulations. Ticks on the $y$ axis are every $0.5^{\circ} \mathrm{C}$. (b) Power spectrum $\left({ }^{\circ} \mathrm{C}^{2}\right.$ cycles $^{-1}$ month $\left.^{-1}\right)$ of N3.4 from detrended observations (HadISST, thick black curve for 1900-2010), CCSM4 (model years 1-1300; dotted curve, from Deser et al. 2012), CCSM4-WSET (dashed curve), and WACCM (3-member ensemble mean 1960-2005).

at high latitudes, and outside of the polar regions the largest warming occurs over the continents, although there is a statistically insignificant cooling of central and eastern North America (not shown). Global changes and changes within the same latitude bands as in Table 3 are summarized in Table 4. The global mean temperature increased by $0.79 \mathrm{~K}$. The warming over land is more than double the warming of the oceans in all latitude bands and is marginally greater in the $\mathrm{SH}$ band compared to $\mathrm{NH}$ band.

In comparison, CCSM4 shows a global increase of $+0.96 \mathrm{~K}$, an increase of $+1.0 \mathrm{~K}$ in the $\mathrm{NH}$, and $+0.88 \mathrm{~K}$ in the $\mathrm{SH}$. The larger temperature increase in CCSM4 compared to WACCM is also reflected in a larger top of the atmosphere net radiative flux $(+0.85$ versus $\left.+0.69 \mathrm{~W} \mathrm{~m}^{-2}\right)$. The largest changes modeled are in CCSM4 in the $21^{\circ}-90^{\circ} \mathrm{N}$ band where an increase of
$1.41 \mathrm{~K}$ is calculated over land. This is $0.43 \mathrm{~K}$ more than predicted by WACCM and is caused by more rapid loss of $\mathrm{NH}$ sea ice in CCSM4. In the SH the sea ice extent losses are similar, as are the differences in temperature.

Changes in both WACCM and CCSM4 are larger than in the Met Office Hadley Centre-University of East Anglia Climatic Research Unit dataset (HadCRUT3) (Brohan et al. 2006). We calculate a global temperature difference of $+0.57 \mathrm{~K}$ between the $1850-70$ and $1986-$ 2005 averages in HadCRUT3. Possible reasons for the larger than observed trend in the models is omission of the indirect effect of sulfate aerosols and an increase in the equilibrium climate sensitivity in CCSM4 relative to the previous version of the model (Meehl et al. 2012).

As can be seen in Table 4, there is a small, but statistically significant, increase of $\sim 0.1 \mathrm{hPa}$ in global mean SLP calculated in both WACCM and CCSM4. However,

TABLE 4. Change in annual-mean surface climate diagnostics between preindustrial conditions and the period 1986-2005. WACCM means calculated from runs 002, 003, and 004 and CCSM4 means calculated from runs 005, 006, and 007. Bold numbers indicate the difference is significant at the $95 \%$ level based on confidence intervals obtained from the preindustrial simulation.

\begin{tabular}{|c|c|c|c|c|c|c|c|}
\hline & Model & $T(\mathrm{~K})$ & $T$ land $(\mathrm{K})$ & $\operatorname{SST}\left({ }^{\circ} \mathrm{C}\right)$ & SLP (hPa) & $P\left(\mathrm{~mm} \mathrm{day}^{-1}\right)$ & $\operatorname{SIE}\left(10^{6} \mathrm{~km}^{2}\right)$ \\
\hline \multirow[t]{2}{*}{ Global } & WACCM & 0.79 & 0.95 & 0.41 & 0.08 & 0.02 & -2.7 \\
\hline & CCSM4 & 0.96 & 1.23 & 0.48 & 0.09 & 0.04 & -3.5 \\
\hline \multirow[t]{2}{*}{$21^{\circ}-90^{\circ} \mathrm{N}$} & WACCM & 0.86 & 0.98 & 0.34 & 0.07 & 0.01 & -0.7 \\
\hline & CCSM4 & 1.24 & 1.41 & 0.39 & -0.07 & 0.03 & -1.4 \\
\hline \multirow[t]{2}{*}{$21^{\circ} \mathrm{S}-21^{\circ} \mathrm{N}$} & WACCM & 0.63 & 0.80 & 0.58 & 0.09 & 0.02 & - \\
\hline & CCSM4 & 0.75 & 0.94 & 0.69 & 0.16 & 0.05 & - \\
\hline \multirow[t]{2}{*}{$21^{\circ}-90^{\circ} \mathrm{S}$} & WACCM & 0.89 & 1.09 & 0.40 & 0.09 & 0.04 & -2.2 \\
\hline & CCSM4 & 0.92 & 1.16 & 0.44 & 0.18 & 0.05 & -2.1 \\
\hline
\end{tabular}


in any particular band the changes are not significant. Similarly, the mean precipitation changes are small $(1 \%-$ $2 \%)$ and only significant in the Southern Hemisphere.

The annual-mean surface temperature anomaly record (globally and by hemisphere) from the three 1955 to 2005 WACCM simulations and the single 1850-2005 historical WACCM simulation are shown in Fig. 7. Anomalies are calculated with respect to the average temperature between 1961 and 1990. For reference, 150 years of annual-mean surface temperature from the WACCM preindustrial control simulation are shown (the time mean has been removed from this series). Consistent with no net radiative flux at the top of the atmosphere, no trend is apparent in the preindustrial time series, indicating that the transient simulation changes are not due to model drift.

Also shown are the anomalies calculated from the HadCRUT3 observational record and anomalies from the seven CCSM4 simulations (also shown in Fig. 4 of Meehl et al. 2012). The single 1850-2005 WACCM simulation is indistinguishable from the CCSM4 simulations. Both model time series track the observations well although, since the anomaly time series are calculated relative to the average over the period 1961-90 (and the overall trends are larger in the model than observations), it is clear that the models fall below the observation early in the time series. In addition, the models show large short-term decreases in temperature following major eruptions such as Krakatoa in 1883, the eruptions in 1902, and Mount Pinatubo in 1991. This has been previously documented in CCSM4 by Gent et al. (2011) and Meehl et al. (2012).

\section{b. NH winter precipitation}

We next examine the changes in $\mathrm{NH}$ winter precipitation over Europe, prompted by the study of Scaife et al. (2012). They compared changes in rainfall in two standard and two high-top models in response to a quadrupling of $\mathrm{CO}_{2}$ and found that models that resolved the stratosphere had consistent differences in the climate change response relative to their low-top versions. While we have not performed a $4 \times \mathrm{CO}_{2}$ experiment, we can examine ensemble-mean precipitation changes between the preindustrial era and present day in CCSM4 and WACCM (shown in Fig. 8). Changes in precipitation in the ensemble of CCSM4 simulations have a similar geographical distribution to changes in response to a $4 \times \mathrm{CO}_{2}$ increase in the two standard models, as shown in Fig. 6 of Scaife et al. (2012). There is an increase in rainfall across most of northern Europe and a drying in the Mediterranean. The changes in CCSM4 are typically from 0.1 to $0.2 \mathrm{~mm} \mathrm{day}^{-1}$. The distribution of the changes in WACCM is similar to CCSM4; however, the amplitude
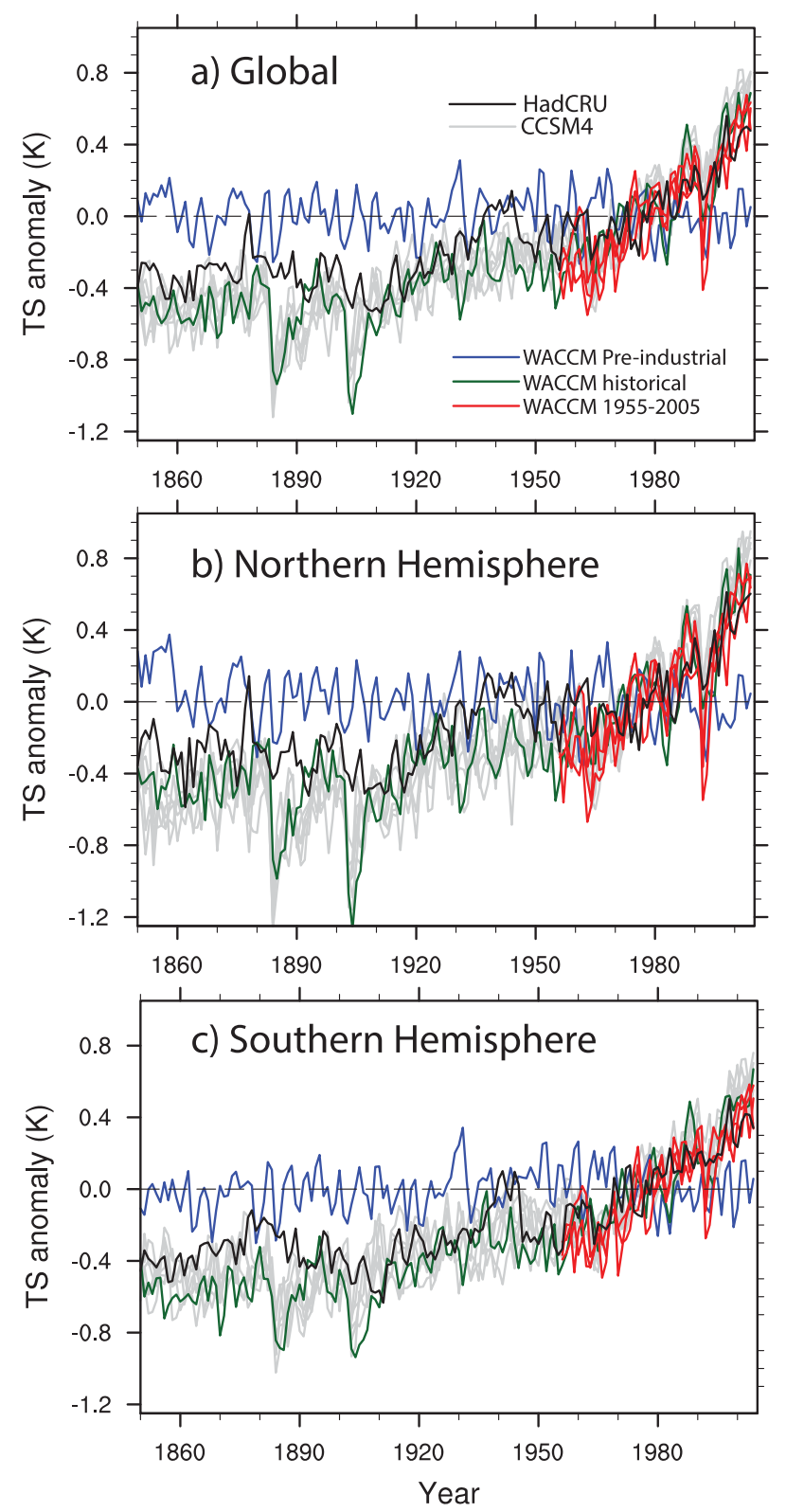

FIG. 7. Annual-mean surface temperature anomaly time series relative to the period 1961-90 (a) averaged globally and (b),(c) by hemisphere: WACCM 1995-2005 simulations (red lines), 18502005 historical simulations with WACCM (green) and CCSM4 (gray), and HadCRUT3 observations (black). CCSM4 data are from runs 005-009, 011, and 012. Shown in blue are temperatures from the WACCM preindustrial simulation with its time mean removed.

of the changes is considerably larger. An increase of greater than $0.6 \mathrm{~mm} \mathrm{day}^{-1}$ is predicted near the Bay of Biscay, more than 3 times the low-top increase. The drying of the Mediterranean is also deeper and more extensive in WACCM compared to CCSM4, and the region of statistically significant drying in WACCM now extends over much of northern Africa, and also 

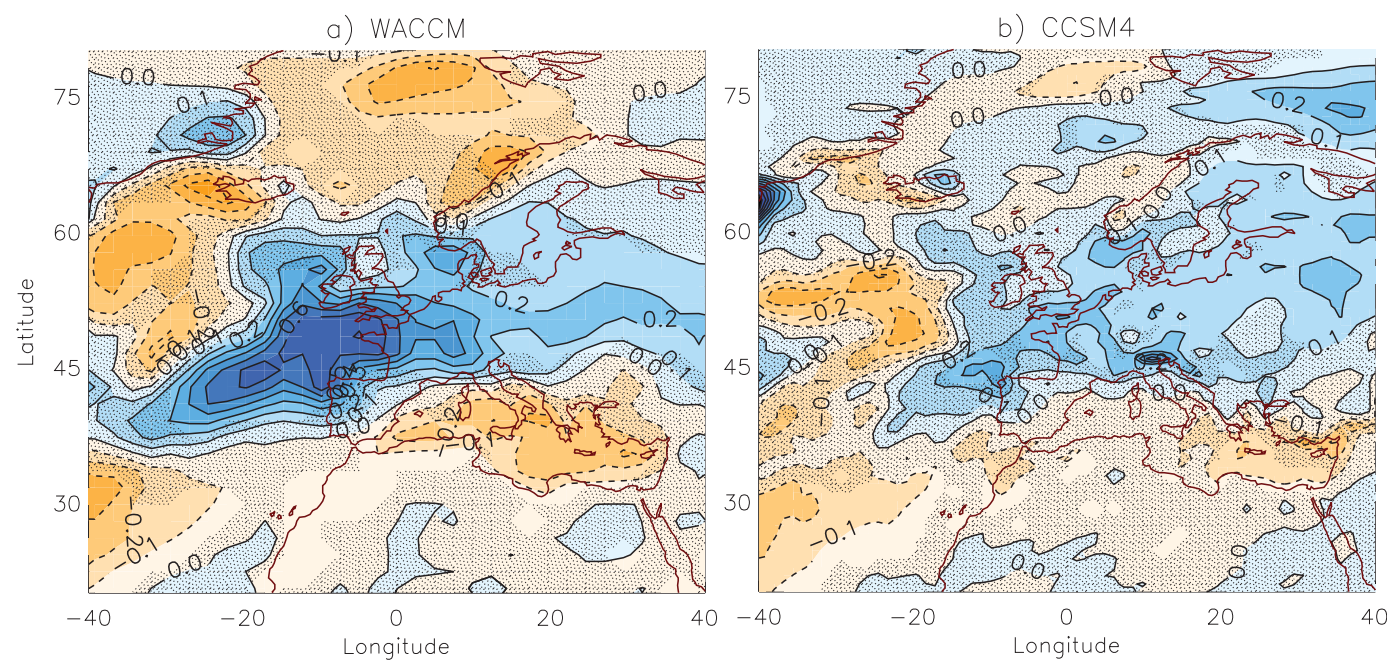

FIG. 8. Ensemble-mean DJF precipitation differences $\left(\mathrm{mm} \mathrm{day}^{-1}\right)$ between preindustrial and present day in (a) WACCM and (b) CCSM4. Differences in unhatched regions are statistically significant at the $95 \%$ level as determined by a $t$ test.

over western Iceland. The exacerbation of the climate change response in precipitation in WACCM relative to CCSM4 is similarly seen in Scaife et al. (2012); there is a remarkable similarity between their Fig. 6a and our Fig. 8a.

\section{c. Circulation changes}

Figure 9 shows the vertical structure of the differences in zonal mean temperature between the preindustrial simulation and model data in Fig. 2. In both January and July there is cooling throughout most of the stratosphere. The cooling is largest in the lower thermosphere and near the stratopause, consistent with an increased infrared emission by $\mathrm{CO}_{2}$ in the $15-\mu \mathrm{m}$ bands. The warming of the high-latitude summer mesosphere in January has been shown to be related to changes in circulation resulting from changes in gravity wave momentum deposition (Smith et al. 2010). They show that the differences are due to a trend in temperature of the lower stratosphere, also seen in Fig. 9. Temperature changes modify stratospheric winds that in turn alter the filtering of gravity waves as they propagate upward through the middle atmosphere. The result is a decrease in the momentum flux divergence at mesopause heights and a reduction in the induced summer to winter circulation, with an associated decrease in adiabatic cooling over the summer pole. a)

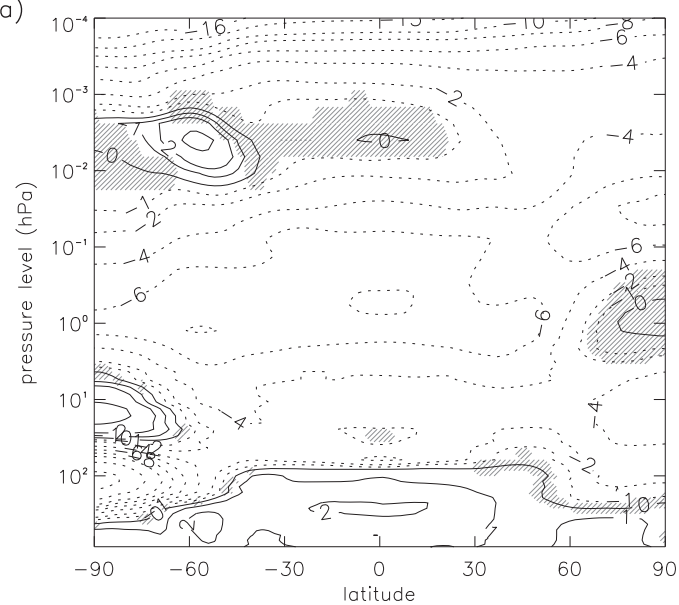

b)

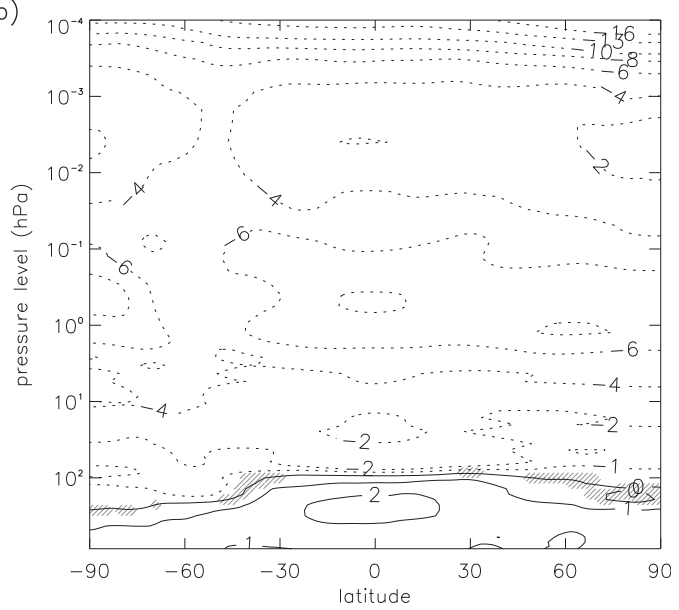

FIG. 9. WACCM zonal-mean monthly mean temperature changes for (a) January and (b) July between preindustrial simulations and the average from 2002 to 2005 shown in Fig. 2. Contour levels (K) are $(-16,-13,-10,-8$, $-6,-4,-2,-1,0,1,2,4,6)$. Differences in unhatched regions are statistically significant at the $95 \%$ level. 


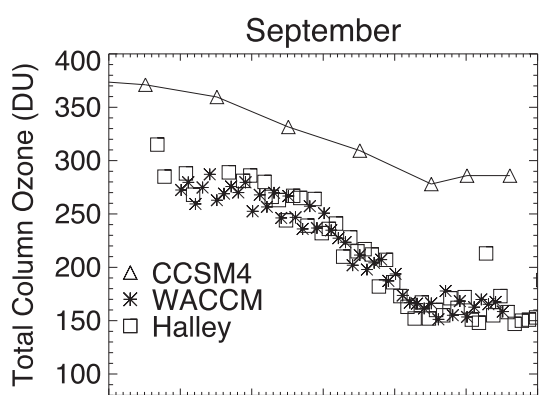

1950196019701980199020002010

December

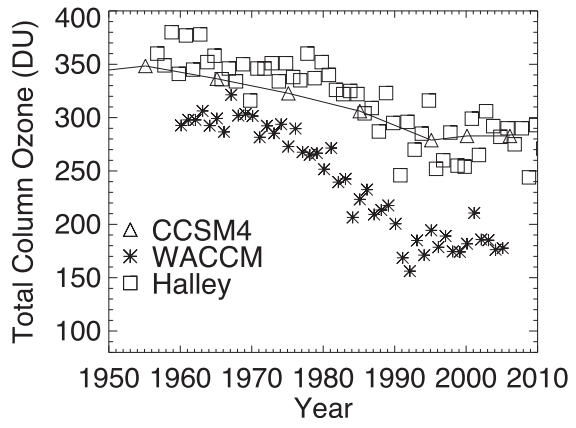

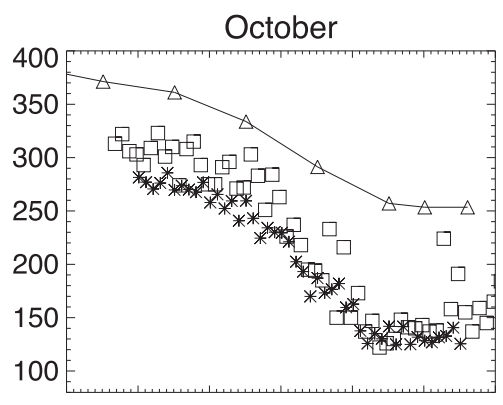

1950196019701980199020002010

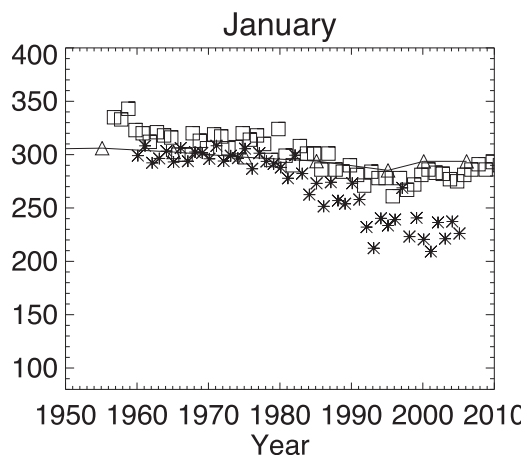

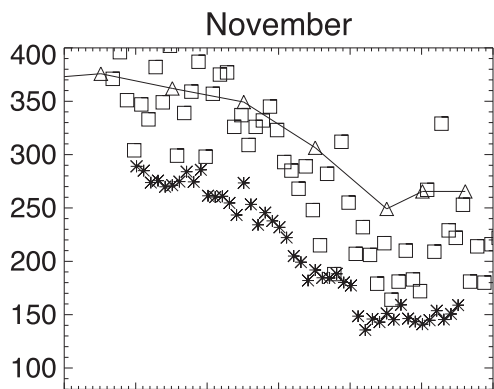

1950196019701980199020002010
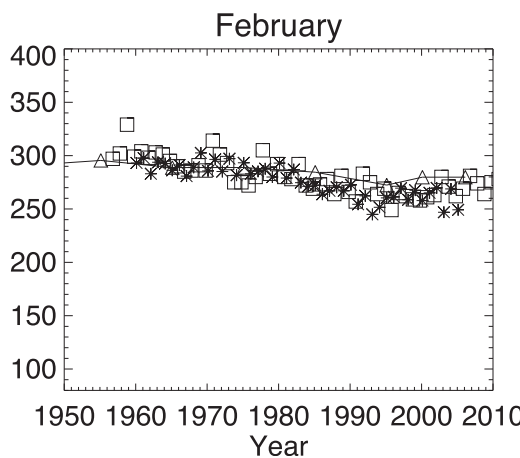

FIG. 10. September-February monthly mean total ozone (DU) in WACCM (asterisk) and observations (squares) at Halley Bay $\left(75^{\circ} \mathrm{S}\right.$, $26^{\circ} \mathrm{W}$ ). Also shown is the specified ozone column used in CCSM4 simulations (solid line and triangles).

The cause of the $>16 \mathrm{~K}$ cooling of the $\mathrm{SH}$ polar lower stratosphere, shown in Fig. 9, is the development of the ozone hole. The loss of ozone significantly reduces radiative heating from the absorption of solar radiation. Historical trends in SH ozone, geopotential height, and temperature in WACCM have been compared to observations in Calvo et al. (2012) and shown to agree to within the error estimates. Figure 10 presents a comparison of the September-February total ozone observed at Halley Bay (J. Shanklin 2011, personal communication). There is excellent agreement between WACCM and observations during September and October when the destruction of ozone by anthropogenic ozone depleting substances (ODS) is at their greatest. WACCM accurately reproduces the long-term decrease in column ozone from approximately 250 Dobson units (DU) in 1960 to 150 DU for present day. During November and December, however, WACCM column ozone underestimates the total ozone column at Halley Bay. This is another symptom of the cold pole problem, wherein the cold temperatures delay the breakup of the polar vortex in spring and prevent transport of air with higher ozone concentrations into the polar region. By February, WACCM again agrees with the observed ozone column. Also shown in Fig. 10 is the total ozone used as input to the CCSM4 CMIP5 simulations (Lamarque et al. 2010; Meehl et al. 2012). It is clear that the CCSM4 specified ozone time series does not have the same deep springtime ozone hole as either WACCM or the observations. Next, we will show that this has significant consequences for temperature trends in the SH lower polar stratosphere.

Monthly mean WACCM and CCSM4 trends between 1979 and 2003 in temperature averaged over the polar cap $\left(60^{\circ}-90^{\circ} \mathrm{S}\right)$ are shown in Fig. 11 . Trends in WACCM reach a maximum in November and December around $50 \mathrm{hPa}$ with values over $4 \mathrm{~K}$ decade $^{-1}$. As shown in Calvo et al. (2012), the amplitude and location of the largest trend in summer agrees well with the observational estimate by Thompson and Solomon (2005). The cooling trend does tend to persist for too long into austral autumn in the lower stratosphere, related to the too strong winter vortex discussed above. This is a common issue to chemistry-climate models (Eyring et al. 2010b). In CCSM4 (Fig. 11b), temperature trends are much lower than both those in WACCM and trends determined from radiosonde measurements (Young et al. 2013). CCSM4 temperature trends do not exceed $-1.5 \mathrm{~K} \mathrm{decade}^{-1}$ at any time, a consequence of the weak ozone hole prescribed in CCSM4 simulations and shown in Fig. 10. This comparison illustrates the necessity of obtaining a realistic ozone trend in the $\mathrm{SH}$ to accurately simulate the observed $\mathrm{SH}$ temperature trends.

The summertime trends in $\mathrm{SH}$ temperature are accompanied by changes in the zonal-mean zonal winds. Figure 12 shows the December-February (DJF) average of the zonal-mean zonal wind and its changes between 

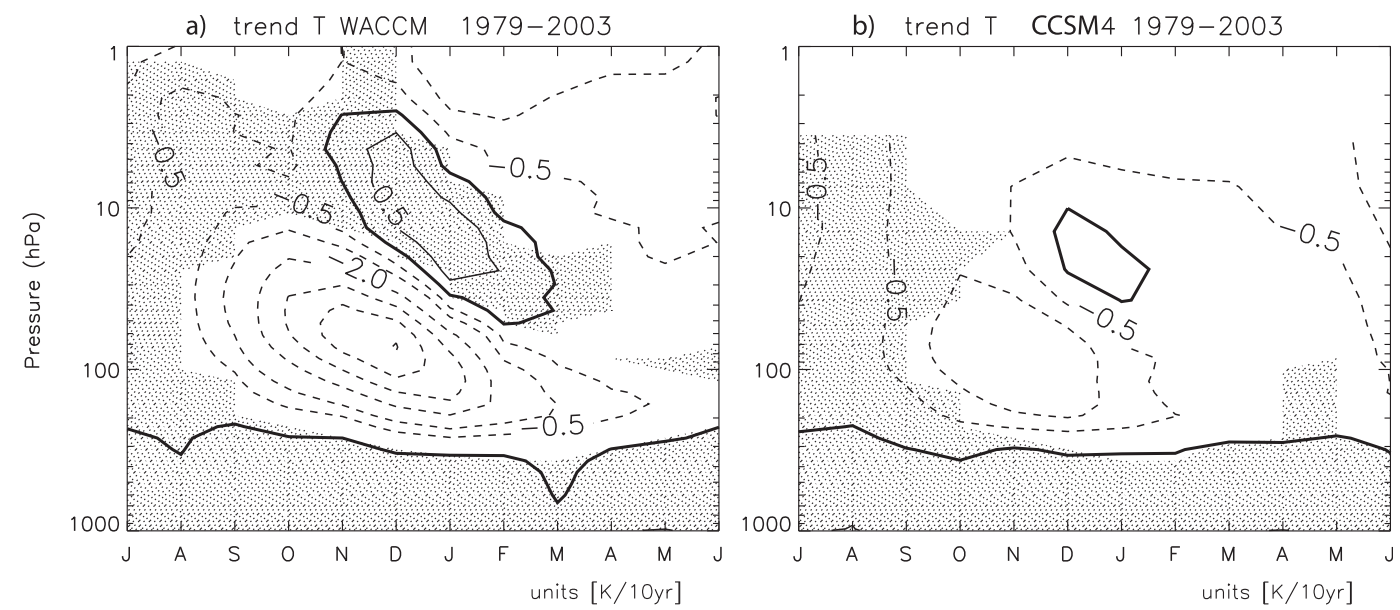

FIG. 11. Ensemble-mean SH polar cap average temperature trend $\left(\mathrm{K}_{\text {decade }}{ }^{-1}\right)$ calculated between 1979 and 2003 in (a) WACCM and (b) CCSM4. Contours at $0, \pm 0.5, \pm 1, \pm 2, \pm 3, \pm 4, \pm 5 \mathrm{~K} \mathrm{decade}^{-1}$. Unhatched regions are statistically significant at the $95 \%$ level as determined by a $t$ test.

the two periods representative of before and during the time of the ozone hole for WACCM, CCSM4, and CCSM4-WSET. Statistically significant changes are mostly limited to latitudes poleward of $40^{\circ}$. As expected, the largest differences between WACCM and CCSM4 simulations occur in the $\mathrm{SH}$ mid and high latitudes. Although the three models show a poleward displacement of the jet in the lower and midstratosphere in the last $25 \mathrm{yr}$ of the simulations, the differences are much larger in WACCM. The larger wind response is consistent with a dynamical response to the stronger ozone-related temperature trends in WACCM (recall that CCSM4-WSET has the same specified ozone as CCSM4). They also indicate that ozone is the primary driver of the changes, rather than increasing greenhouse gases, which are constrained to be the same across all models.
Accompanying the shift in the midlatitude summertime jet is a change in near-surface zonal winds and precipitation. Trends in these quantities over the period from 1975 to 1995 are shown Fig. 13. In WACCM, wind changes are largest near $65^{\circ} \mathrm{S}$, and precipitation changes largest at $70^{\circ} \mathrm{S}$; both show an increasing trend of $\sim 10 \%$ decade ${ }^{-1}$. There is also a decreasing trend in winds and precipitation at lower latitudes (peaking around $45^{\circ}$ and $50^{\circ} \mathrm{S}$, respectively). Overall, the changes are much weaker in CCSM4 and CCSM4-WSET. It should also be noted that in WACCM the locations of the local maxima change in zonal winds are shifted poleward relative to the low-top models. For example, the maximum positive trend in CCSM4 zonal winds occurs at $60^{\circ} \mathrm{S}$. As before, since the changes in greenhouse gases are the same in all models, it suggests the differing trends are primarily
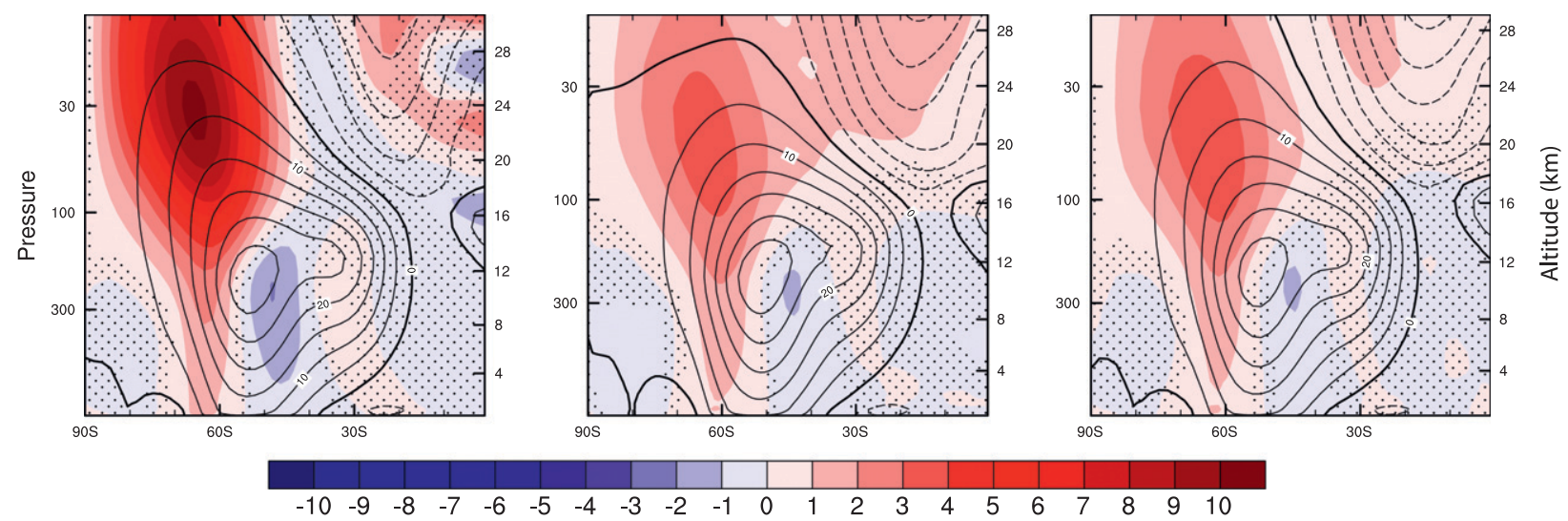

FIG. 12. Southern Hemisphere DJF zonal wind for (left) WACCM, (middle) CCSM4, and (right) CCSM4-WSET. Colors are difference for 1986-2005 average minus 1960-79 average. Contour lines are 1960-79 average every $5 \mathrm{~m} \mathrm{~s}^{-1}$. Differences in unhatched regions are statistically significant at the $95 \%$ level as determined by a $t$ test. 

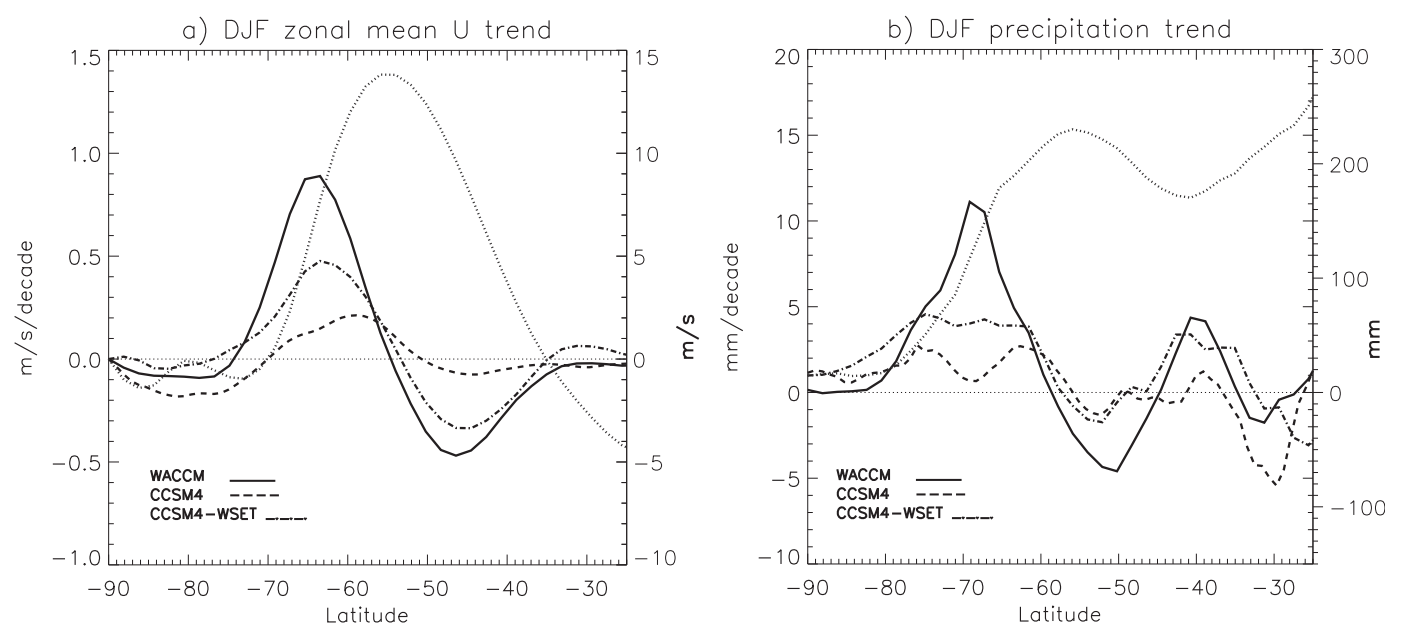

FIG. 13. Latitudinal distribution of the trend in (a) the zonal wind at $850 \mathrm{hPa}\left(\mathrm{m} \mathrm{s}^{-1} \mathrm{decade}^{-1}\right.$ ) and (b) precipitation $\left(\mathrm{mm} \mathrm{decade}^{-1}\right)$ in austral summer (DJF) for the period 1975-95 (December 1974-November 1995). The solid line is the WACCM ensemble mean (3 members), dashed-dotted line is CCSM4-WSET ensemble mean (3 members), and the dashed line is CCSM4 ensemble mean ( 5 members). The dotted line shows the DJF climatology [right scale in (a) $\mathrm{m} \mathrm{s}^{-1}$ and (b) $\mathrm{mm}$ ] for the same period in WACCM.

driven by the difference in stratospheric trends presented above.

Just as in the NH, the southern annular mode (SAM) index can be calculated as the principal component of the leading empirical orthogonal function of geopotential height or winds. Alternatively, it can be calculated simply as the difference in zonally averaged SLP between $40^{\circ}$ and $65^{\circ} \mathrm{S}$ (Marshall 2003). Given the large trends in tropospheric temperature and winds shown above, it is expected that the SAM index would also be changing (see, e.g., Perlwitz et al. 2008). We compare model seasonal SAM index trends per decade calculated over the period from 1960 to 2000 for the months March-May (MAM), June-August (JJA), September-November (SON), and December-February (DJF) in Table 5. As in the studies of Arblaster and Meehl (2006), we chose the definition of Marshall (2003) to enable comparison with previous studies. For all models the trend in summer (DJF) is positive and statistically significant at the $95 \%$ level. Unexpectedly, the strongest trend of $0.75 \mathrm{hPadecade}{ }^{-1}$ is found in CCSM4 simulations, and the trend weakest in WACCM $\left(0.27 \mathrm{hPa}\right.$ decade $\left.^{-1}\right)$. In other seasons and in the annual mean the trends are not statistically different from zero. Also shown are trends in the observed SAM from Table 3 of Marshall (2003) calculated between 1958 and 2000. The observed DJF trend is similarly positive and significant at the $90 \%$ level, but larger than any modeled trend. Figure 14 shows graphically the SAM trends by season and annually for the individual simulations as well as the ensemble-mean trends listed in Table 5. The figure illustrates the large degree of variability across the ensemble, especially in winter. A similar trend analysis was performed on simulations from 17 models, 11 of which had varying ozone, by Fogt et al. (2009). While they similarly found a significant summer SAM trend in all models with ozone, they also found a significant (if smaller) trend in autumn. This does not appear to be the case in CCSM4 or WACCM.

As noted above, the maximum changes in the midlatitude zonal winds occur at higher latitudes in WACCM than CCSM4. Since the trends in winds in WACCM are much larger than in CCSM4, it is likely that the fixed latitudes used to calculate the SAM index $\left(40^{\circ}\right.$ and $\left.65^{\circ} \mathrm{S}\right)$ are not ideally located to measure the surface pressure

TABLE 5. Model trends from 1960 to 2000 of the SAM index $\left(\mathrm{hPa}\right.$ decade $\left.{ }^{-1}\right)$. The SAM index is defined as the difference in zonally averaged sea level pressure between $40^{\circ}$ and $65^{\circ} \mathrm{S}$. The $2 \sigma$ errors on the fit are given in parentheses. Observational trends are from Marshall (2003) calculated over the period 1958-2000.

\begin{tabular}{|c|c|c|c|c|c|}
\hline & Annual & Autumn (MAM) & Winter (JJA) & Spring (SON) & Summer (DJF) \\
\hline Observations & $0.62( \pm 0.63)$ & $0.82( \pm 1.1)$ & $0.71( \pm 1.19)$ & $0.0( \pm 1.11)$ & $1.05( \pm 1.35)$ \\
\hline WACCM & $0.17( \pm 0.25)$ & $-0.02( \pm 0.30)$ & $0.13( \pm 0.61)$ & $0.29( \pm 0.35)$ & $0.27( \pm 0.24)$ \\
\hline CCSM4-WSET & $0.11( \pm 0.20)$ & $0.11( \pm 0.23)$ & $-0.18( \pm 0.51)$ & $0.05( \pm 0.38)$ & $0.36( \pm 0.28)$ \\
\hline CCSM4 & $0.25( \pm 0.26)$ & $0.15( \pm 0.28)$ & $0.04( \pm 0.63)$ & $0.11( \pm 0.55)$ & $0.75( \pm 0.36)$ \\
\hline
\end{tabular}



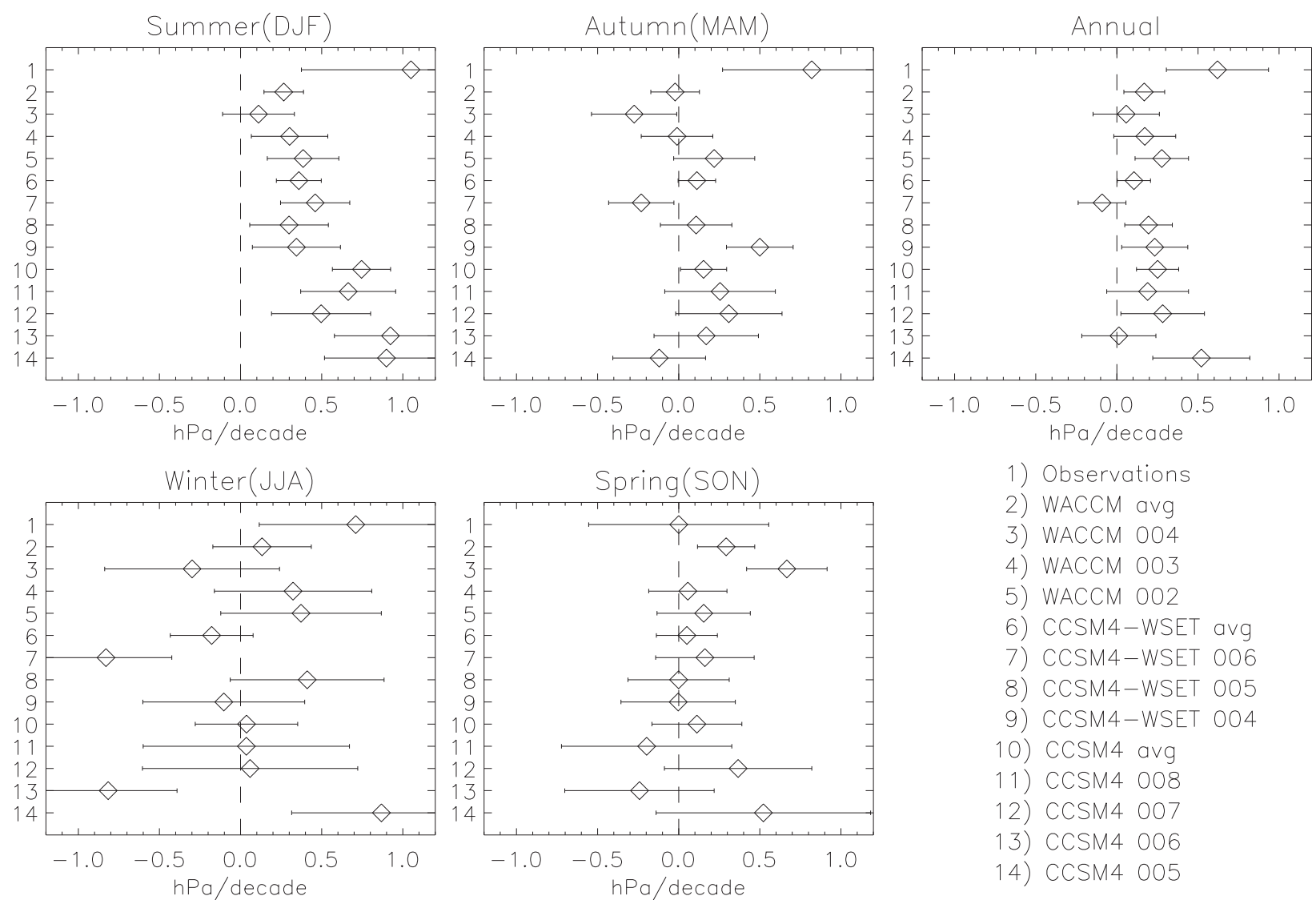

1) Observations

2) WACCM avg

3) WACCM 004

4) WACCM 003

5) WACCM 002

6) CCSM4-WSET avg

7) CCSM4-WSET 006

8) CCSM4-WSET 005

9) CCSM4-WSET 004

10) $\operatorname{ccsm} 4$ avg

11) $\operatorname{ccsM} 4008$

12) $\operatorname{ccsm} 4007$

13) $\operatorname{ccsm} 4006$

14) $\operatorname{ccsm} 4005$

FIG. 14. Trends in the seasonal SAM index $\left(\mathrm{hPa} \mathrm{decade}^{-1}\right)$ for observations (Marshall 2003) and different runs of CCSM and WACCM for the period 1960-2000. The SAM index is defined as the difference in zonally averaged sea level pressure between $40^{\circ}$ and $65^{\circ} \mathrm{S}$. Error bars are $1 \sigma$ uncertainties on the linear trend.

response in WACCM. If instead, the SAM index were calculated as the difference between SLP at $71^{\circ}$ and $46^{\circ} \mathrm{S}$, the ensemble-mean trend in DJF in WACCM would be $0.84( \pm 0.36) \mathrm{hPa}$ decade $^{-1}$; that is, a poleward shift in latitude of $6^{\circ}$ would lead to more than a threefold increase in estimated SAM trend.

\section{d. Antarctic sea ice}

Antarctic sea ice extent has been observed to be increasing since the late 1970s, and it has been postulated that the increase may be related to the positive trend in the SAM (Turner et al. 2009). Since WACCM does reproduce a positive SAM trend, albeit smaller than observed, we now analyze SIE changes in the WACCM ensemble. The annual cycle of SIE for preindustrial conditions and present day are shown in Fig. 15a along with the observed cycle (see Fig. 1 in Landrum et al. 2012). Annually averaged SIE between 1979 and 2005 is $1.44 \times 10^{7} \mathrm{~km}^{2}$, which is larger than the observed value of $1.19 \times 10^{7} \mathrm{~km}^{2}$ but an improvement over the CCSM4 value of $1.83 \times 10^{7} \mathrm{~km}^{2}$. Most of the discrepancy between
WACCM and the observations comes from a failure to reproduce the seasonal retreat in SIE that reaches a minimum SIE in March. WACCM agrees with observations between August and November, during which time coverage reaches a maximum of approximately $1.9 \times 10^{7} \mathrm{~km}^{2}$.

Comparing preindustrial to present-day coverage, the annually averaged SIE relative loss in WACCM is $14 \%$, whereas it is $12 \%$ in CCSM4. Loss rates are largest in February and March: almost 20\% in WACCM and 16\% in CCSM4. The biggest differences in loss rates occur during the months of January and February. The relative changes for all months in SIE are summarized in Fig. 15b. One possible cause of this accelerated loss of coverage in WACCM relative to CCSM4 is the development of the ozone hole, which has been shown above to be more pronounced (and more realistic) in WACCM. If, instead, sea ice extent is compared between 1850 and the period 1960-79, prior to significant anthropogenic ODSdriven ozone loss, the SIE relative losses are remarkably similar (also shown in Fig. 15b). The annually averaged 
a)

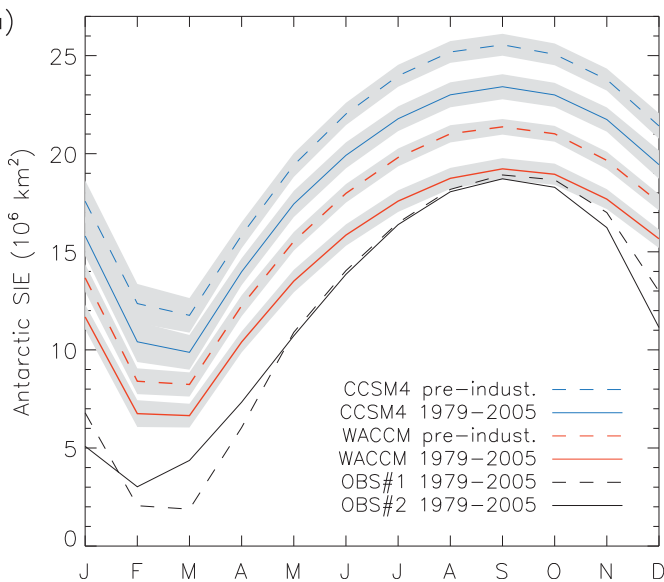

b)

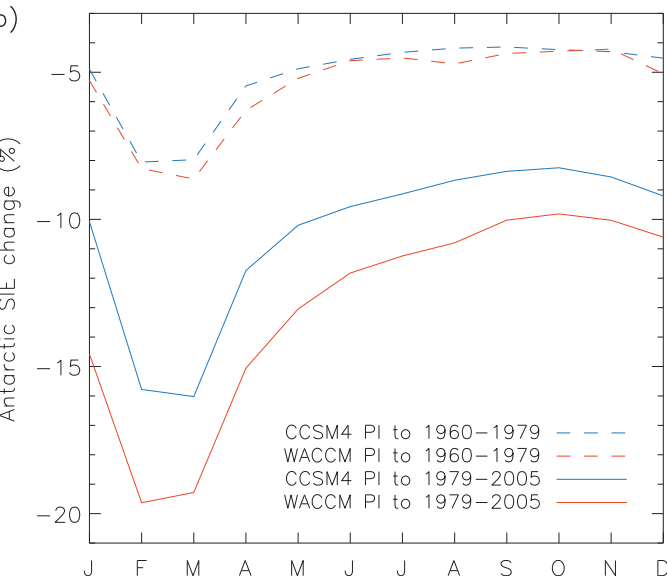

FIG. 15. (a) Annual cycle of Antarctic SIE $\left(10^{6} \mathrm{~km}^{2}\right)$ for WACCM averaged between 1979 and 2005 (solid red line) and preindustrial (dashed red line). Shading indicates sample variance. CCSM4 1979-2005 (solid blue line), preindustrial (dashed blue line), and two estimates of the observed SIE for 1979-2005 (black lines) from Landrum et al. (2012). (b) Relative percentage change in SIE from preindustrial conditions to 1979-2005 (solid lines) and preindustrial conditions to 1960-79 (dashed) and for ensemble means of WACCM (red) and CCSM4 (blue) simulations.

SIE relative loss in both WACCM and CCSM4 is 5.5\%, and both models show between $8 \%$ and $9 \%$ loss in February and March. The agreement in trends suggests that the changes are driven by greenhouse gas increases, which are the same in both models. It illustrates that more than half of the SIE losses over the last 150 years have happened after 1975 and that changes since then are larger in a model with a better representation of stratospheric ozone loss.

This result is consistent with the modeling study of Sigmond and Fyfe (2010) that simulated a decrease throughout the year in SIE in response to stratospheric ozone depletion. It is also consistent with the recent study of Smith et al. (2012), which compares future simulations using WACCM where ozone depleting substances (ODS) were held fixed or allowed to decrease into the future. That study clearly shows that SIE losses are greater in the simulation where the ozone hole does not recover. In both studies, increased losses were related to changes in Ekman sea ice transport and a warming of the upper ocean in the cases with stratospheric ozone depletion. However, it should be noted that the predicted trends in WACCM and CCSM4 are at odds with the observed trend over the past 30 years (Turner et al. 2009).

\section{Summary}

In this paper, we have compared the climate and its variability in long-term CMIP5 simulations from the preindustrial era to present day using two NCAR models: CESM1(WACCM) and CCSM4. The surface temperature records simulated are indistinguishable from each other and track the observed record, with the exception that both models overestimate the short-term cooling following large volcanic eruptions. The ensemble-mean WACCM global-mean surface temperature at the end of the twentieth century is $0.79 \mathrm{~K}$ warmer than during the preindustrial era. Increasing greenhouse gases and the late twentieth-century development of the Antarctic ozone hole lead to an overall cooling of the stratosphere and mesosphere. Cooling at the stratopause is approximately $8 \mathrm{~K}$, and in the $\mathrm{SH}$ summer polar lower stratosphere it is over $16 \mathrm{~K}$.

The frequency of tropospheric midlatitude blocking events and ENSO in WACCM are very similar to those in CCSM4. As in CCSM4, the amplitude of ENSO is too large. An area where the models differ significantly is in the representation of $\mathrm{NH}$ winter polar stratosphere variability. We find that the frequency and seasonal distribution of NH SSWs in WACCM are realistic, whereas in CCSM4 they are almost completely absent. As a consequence, perturbations in the northern annular mode related to these stratospheric sudden warmings fail to propagate into the polar troposphere in CCSM4. The source of this difference appears to be partly related to having a fully resolved stratosphere and partly to the inclusion in WACCM of a parameterization of surface stress due to unresolved topography. Inclusion of a stratosphere also modifies the response of $\mathrm{NH}$ winter precipitation to increasing greenhouse gases in agreement with a previous study. In particular, WACCM predicts significantly larger changes in precipitation over Europe, the Mediterranean, and northern Africa. The differences in predicted changes between the two models 
can be larger than the magnitude of the climate change prediction itself.

In comparison to both observations and WACCM, CCSM4 predicts too weak of a trend in SH lowerstratospheric polar temperatures: a consequence of a specified ozone climatology that has insufficient anthropogenic ODS-driven ozone losses. The weaker trends in CCSM4 lead to weaker changes in the midlatitude summertime jet, precipitation, and near-surface winds. The trends, as well as the differences between WACCM and CCSM4, are consistent with previous model analysis (e.g., Son et al. 2009; Polvani et al. 2011).

However, analysis of a standard diagnostic for the SAM (zonal mean SLP differences) produces weaker trends in WACCM over the last 30 years, raising the question as to whether the SLP-based SAM index is the most appropriate index to describe the coupling process between the atmosphere and the ocean and sea ice. Analysis is ongoing using, instead, an EOF-based SAM index that should represent the surface variability more accurately.

We find that the Antarctic sea ice extent is more realistic in WACCM but that both models predict a similar decrease in SIE from the preindustrial era to 1970. Consistent with the studies of Smith et al. (2012) and Sigmond and Fyfe (2010), there is an acceleration of SIE loss in WACCM relative to CCSM4 since the 1970s, which does not support the argument that the observed positive trend in SIE since then is related to the development of the Antarctic ozone hole.

Overall, we find that the addition of a fully resolved stratosphere, with realistic trends and variability, produces significant differences in the climate change predictions from the preindustrial era to present day. When quantifying uncertainty in past and future climate change predictions, it will be important to consider the systematic errors introduced by the choices made on how the upper atmosphere is represented in the model.

Acknowledgments. We thank Rolando Garcia, Marianna Vertenstein, Christopher Fischer, Francis Vitt, and Fabrizio Sassi for assistance in developing CESM1 (WACCM) and interpreting its output. We also thank Edwin Gerber for discussions on deriving a simplified NAM index and Rich Neale and David Barriopedro for advice on the calculation of blocking frequency. The CESM project is supported by the National Science Foundation and the Office of Science (BER) of the U.S. Department of Energy. Computing resources were provided by the Climate Simulation Laboratory at NCAR's Computational and Information Systems Laboratory (CISL), sponsored by the National Science Foundation and other agencies. This research was enabled by CISL compute and storage resources. Bluefire, a 4064-processor IBM Power6 resource with a peak of 77 TeraFLOPS, provided more than 7.5 million computing hours, the GLADE high-speed disk resources provided 0.4 PetaBytes of dedicated disk, and CISL's 12-PB HPSS archive provided over 1 PetaByte of storage in support of this research project. LMP is supported in part by a grant from the U.S. National Science Foundation to Columbia University.

\section{REFERENCES}

Ammann, C. M., 2003: A monthly and latitudinally varying volcanic forcing dataset in simulations of 20th century climate. Geophys. Res. Lett., 30, 1657, doi:10.1029/2003GL016875.

Arblaster, J., and G. A. Meehl, 2006: Contributions of external forcings to southern annular mode trends. J. Climate, 19, 28962905.

Baldwin, M. P., and T. Dunkerton, 2001: Stratospheric harbingers of anomalous weather regimes. Science, 294, 581-584, doi:10.1126/ science.1063315.

— , and D. W. Thompson, 2009: A critical comparison of stratosphere-troposphere coupling indices. Quart. J. Roy. Meteor. Soc., 135, 1661-1672, doi:10.1002/qj.479.

Boville, B. A., 1995: Middle atmosphere version of CCM2 (MACCM2): Annual cycle and interannual variability. J. Geophys. Res., 100 (D5), 9017-9039.

Brohan, P., J. J. Kennedy, I. Harris, S. F. B. Tett, and P. D. Jones, 2006: Uncertainty estimates in regional and global observed temperature changes: A new data set from 1850. J. Geophys. Res., 111, D12106, doi:10.1029/2005JD006548.

Butler, A. H., and L. M. Polvani, 2011: El Niño, La Niña, and stratospheric sudden warmings: A reevaluation in light of the observational record. Geophys. Res. Lett., 38, L13807, doi:10.1029/2011GL048084.

Calvo, N., R. R. Garcia, W. J. Randel, and D. R. Marsh, 2010: Dynamical mechanism for the increase in tropical upwelling in the lowermost tropical stratosphere during warm ENSO events. J. Atmos. Sci., 67, 2331-2340.

,- — D. R. Marsh, M. J. Mills, D. E. Kinnison, and P. J. Young, 2012: Reconciling modeled and observed temperature trends over Antarctica. Geophys. Res. Lett., 39, L16803, doi:10.1029/2012GL052526.

Castanheira, J. M., and D. Barriopedro, 2010: Dynamical connection between tropospheric blockings and stratospheric polar vortex. Geophys. Res. Lett., 37, L13809, doi:10.1029/ 2010GL043819.

Charlton, A. J., and L. M. Polvani, 2007: A new look at stratospheric sudden warmings. Part I: Climatology and modeling benchmarks. J. Climate, 20, 449-469.

Charlton-Perez, A. J., and Coauthors, 2013: On the lack of stratospheric dynamical variability in low-top versions of the CMIP5 models. J. Geophys. Res. Atmos., 118, 2494-2505, doi:10.1002/jgrd.50125.

Danabasoglu, G., S. C. Bates, B. P. Briegleb, S. R. J. M. Jochum, W. G. Large, S. Peacock, and S. G. Yeager, 2012: The CCSM4 ocean component. J. Climate, 25, 1361-1389.

D'Andrea, F., and Coauthors, 1998: Northern Hemisphere atmospheric blocking as simulated by 15 atmospheric general circulation models in the period 1979-1988. Climate Dyn., 14, 385-407, doi:10.1007/s003820050230. 
de Boer, G., W. Chapman, J. E. Kay, B. Medeiros, M. D. Shupe, S. Vavrus, and J. Walsh, 2012: A characterization of the presentday Arctic atmosphere in CCSM4. J. Climate, 25, 2676-2695.

de la Torre, L., R. R. Garcia, D. Barriopedro, and A. Chandran, 2012: Climatology and characteristics of stratospheric sudden warmings in the Whole Atmosphere Community Climate Model. J. Geophys. Res., 117, D04110, doi:10.1029/ 2011JD016840.

Deser, C., and Coauthors, 2012: ENSO and Pacific decadal variability in the Community Climate System Model version 4 . J. Climate, 25, 2622-2651.

Eyring, V., and Coauthors, 2007: Multimodel projections of stratospheric ozone in the 21st century. J. Geophys. Res., 112, D16303, doi:10.1029/2006JD008332.

_- and Coauthors, 2010a: Multi-model assessment of stratospheric ozone return dates and ozone recovery in CCMVal-2 models. Atmos. Chem. Phys., 10, 9451-9472, doi:10.5194/ acp-10-9451-2010.

—, T. Shepherd, and D. Waugh, Eds., 2010b: Stratospheric processes and their role in climate: SPARC report on the evaluation of chemistry-climate models. WCRP-132, WMO/ TD-1526, SPARC Rep. 5, 408 pp. [Available online at http:// www.sparc-climate.org/publications/sparc-reports/.]

Fogt, R. L., J. Perlwitz, A. J. Monaghan, D. H. Bromwich, J. M. Jones, and G. J. Marshall, 2009: Historical SAM variability. Part II: Twentieth-century variability and trends from reconstructions, observations, and the IPCC AR4 models. J. Climate, 22, 5346-5365.

Forster, P., and Coauthors, 2007: Changes in atmospheric constituents and in radiative forcing. Climate Change 2007: The Physical Science Basis, S. Solomon et al., Eds., Cambridge University Press, 129-234.

Garcia, R. R., D. R. Marsh, D. E. Kinnison, B. A. Boville, and F. Sassi, 2007: Simulation of secular trends in the middle atmosphere, 1950-2003. J. Geophys. Res., 112, D09301, doi:10.1029/2006JD007485.

Gent, P. R., and Coauthors, 2011: The Community Climate System Model version 4. J. Climate, 24, 4973-4991.

Gerber, E. P., and Coauthors, 2010: Stratosphere-troposphere coupling and annular mode variability in chemistry-climate models. J. Geophys. Res., 115, D00M06, doi:10.1029/ 2009JD013770

—_, and Coauthors, 2012: Assessing and understanding the impact of stratospheric dynamics and variability on the earth system. Bull. Amer. Meteor. Soc., 93, 845-859.

Holland, M. M., D. A. Bailey, B. P. Briegleb, B. Light, and E. Hunke, 2012: Improved sea ice shortwave radiation physics in CCSM4: The impact of melt ponds and aerosols on Arctic sea ice. J. Climate, 25, 1413-1430.

Jackman, C., D. R. Marsh, F. M. Vitt, R. R. Garcia, C. E. Randall, E. L. Fleming, and S. M. Frith, 2009: Long-term middle atmospheric influence of very large solar proton events. J. Geophys. Res., 114, D11304, doi:10.1029/2008JD011415.

Kinnison, D. E., and Coauthors, 2007: Sensitivity of chemical tracers to meteorological parameters in the MOZART-3 chemical transport model. J. Geophys. Res., 112, D20302, doi:10.1029/ 2006JD007879.

Kopp, G., and J. L. Lean, 2011: A new, lower value of total solar irradiance: Evidence and climate significance. Geophys. Res. Lett., 38, L01706, doi:10.1029/2010GL045777.

Kushner, P. J., 2010: Annular modes of the troposphere and stratosphere. The Stratosphere: Dynamics, Transport, and Chemistry, Geophys. Monogr., Vol. 190, Amer. Geophys. Union, 59-91.
Lamarque, J.-F., and Coauthors, 2010: Historical (1850-2000) gridded anthropogenic and biomass burning emissions of reactive gases and aerosols: Methodology and application. Atmos. Chem. Phys., 10, 7017-7039, doi:10.5194/acp-10-7017-2010.

Landrum, L., M. Holland, D. Schneider, and E. Hunke, 2012: Antarctic sea ice climatology, variability, and late twentiethcentury change in CCSM4. J. Climate, 25, 4817-4838.

Lean, J., G. Rottman, J. Harder, and G. Kopp, 2005: SORCE contributions to new understanding of global change and solar variability. Sol. Phys., 230, 27-53, doi:10.1007/ s11207-005-1527-2.

Marsh, D. R., R. R. Garcia, D. E. Kinnison, B. A. Bouville, F. Sassi, S. C. Solomon, and K. Matthes, 2007: Modeling the whole atmosphere response to solar cycle changes in radiative and geomagnetic forcing. J. Geophys. Res., 112, D23306, doi:10.1029/2006JD008306.

Marshall, G. J., 2003: Trends in the southern annular mode from observations and reanalyses. J. Climate, 16, 4134-4143.

Martius, O., L. M. Polvani, and H. C. Davies, 2009: Blocking precursors to stratospheric sudden warming events. Geophys. Res. Lett., 36, L14806, doi:10.1029/2009GL038776.

Matthes, K., D. R. Marsh, R. R. Garcia, D. E. Kinnison, F. Sassi, and S. Walters, 2010: Role of the QBO in modulating the influence of the 11 year solar cycle on the atmosphere using constant forcings. J. Geophys. Res., 115, D18110, doi:10.1029/ 2009JD013020.

Meehl, G. A., and Coauthors, 2012: Climate system response to external forcings and climate change projections in CCSM4. J. Climate, 25, 3661-3683.

Meinshausen, M., and Coauthors, 2011: The RCP greenhouse gas concentrations and their extensions from 1765 to 2300. Climatic Change, 109, 213-241, doi:10.1007/s10584-011-0156-z.

Morgenstern, O., and Coauthors, 2010: Review of the formulation of present-generation stratospheric chemistry-climate models and associated external forcings. J. Geophys. Res., 115, D00M02, doi:10.1029/2009JD013728.

Neale, R., J. Richter, S. Park, P. Lauritzen, S. Vavrus, P. Rasch, and M. Zhang, 2013: The mean climate of the Community Atmosphere Model (CAM4) in forced SST and fully coupled experiments. J. Climate, 26, 5150-5168.

Perlwitz, J., S. Pawson, R. Fogt, J. Nielsen, and W. Neff, 2008: Impact of stratospheric ozone hole recovery on Antarctic climate. Geophys. Res. Lett., 35, L08714, doi:10.1029/ 2008 GL033317.

Polvani, L. M., D. W. Waugh, G. J. P. Correa, and S.-W. Son, 2011: Stratospheric ozone depletion: The main driver of twentiethcentury atmospheric circulation changes in the Southern Hemisphere. J. Climate, 24, 795-812.

Rayner, N. A., D. E. Parker, E. B. Horton, C. K. Folland, L. V. Alexander, D. P. Rowell, E. C. Kent, and A. Kaplan, 2003: Global analyses of sea surface temperatures, sea ice, and night marine air temperature since the late nineteenth century. J. Geophys. Res., 108, 4407, doi:10.1029/2002JD002670.

Remsberg, E. E., and Coauthors, 2008: Assessment of the quality of the version 1.07 temperature-versus-pressure profiles of the middle atmosphere from TIMED/SABER. J. Geophys. Res., 113, D17101, doi:10.1029/2008JD010013.

Richter, J. H., F. Sassi, and R. R. Garcia, 2010: Toward a physically based gravity wave source parameterization in a general circulation model. J. Atmos. Sci., 67, 136-156.

Rienecker, M. M., and Coauthors, 2011: MERRA: NASA's Modern-Era Retrospective Analysis for Research and Applications. J. Climate, 24, 3624-3648. 
Sander, S. P., and Coauthors, 2006: Chemical kinetics and photochemical data for use in atmospheric studies. JPL Publ. 06-2, 523 pp.

Sassi, F., D. Kinnison, B. A. Boville, R. R. Garcia, and R. Roble, 2004: Effect of El Niño-Southern Oscillation on the dynamical, thermal, and chemical structure of the middle atmosphere. J. Geophys. Res., 109, D17108, doi:10.1029/2003JD004434.

Scaife, A. A., T. Woollings, J. Knight, G. Martin, and T. Hinton, 2010: Atmospheric blocking and mean biases in climate models. J. Climate, 23, 6143-6152.

_- and Coauthors, 2012: Climate change projections and stratosphere-troposphere interaction. Climate Dyn., 38, 20892097, doi:10.1007/s00382-011-1080-7.

Sigmond, M., and J. C. Fyfe, 2010: Has the ozone hole contributed to increased Antarctic sea ice extent? Geophys. Res. Lett., 37, L18502, doi:10.1029/2010GL044301.

Smith, A. K., R. R. Garcia, D. R. Marsh, D. E. Kinnison, and J. H. Richter, 2010: Simulations of the response of mesospheric circulation and temperature to the Antarctic ozone hole. Geophys. Res. Lett., 37, L22803, doi:10.1029/2010GL045255.

Smith, K. L., L. M. Polavani, and D. R. Marsh, 2012: Mitigation of 21st century Antarctic sea ice loss by stratospheric ozone recovery. Geophys. Res. Lett., 39, L20701, doi:10.1029/ 2012 GL053325.

Son, S.-W., N. F. Tandon, L. M. Polvani, and D. W. Waugh, 2009: Ozone hole and Southern Hemisphere climate change. Geophys. Res. Lett., 36, L15705, doi:10.1029/2009GL038671.

Swinbank, R., and D. A. Ortland, 2003: Compilation of wind data for the Upper Atmosphere Research Satellite (UARS)
Reference Atmosphere Project. J. Geophys. Res., 108, 4615, doi:10.1029/2002JD003135.

Tabazadeh, A., O. B. Toon, S. L. Clegg, and P. Hamill, 1997: A new parameterization of $\mathrm{H}_{2} \mathrm{SO}_{4} / \mathrm{H}_{2} \mathrm{O}$ aerosol composition: Atmospheric implications. Geophys. Res. Lett., 24, 1931-1934, doi:10.1029/97GL01879.

Taylor, K., R. Stouffer, and G. Meehl, 2012: An overview of CMIP5 and the experiment design. Bull. Amer. Meteor. Soc., 93, 485498.

Thompson, D. W. J., and S. Solomon, 2005: Recent stratospheric climate trends as evidenced in radiosonde data: Global structure and tropospheric linkages. J. Climate, 18, 4785-4795.

Tilmes, S., R. Müller, and R. J. Salawitch, 2008: The sensitivity of polar ozone depletion to proposed geoengineering schemes. Science, 320, 1201-1204, doi:10.1126/science.1153966.

, R. R. Garcia, D. E. Kinnison, A. Gettelman, and P. J. Rasch, 2009: Impact of geoengineered aerosols on the troposphere and stratosphere. J. Geophys. Res., 114, D12305, doi:10.1029/ 2008JD011420.

Turner, J., and Coauthors, 2009: Non-annular atmospheric circulation change induced by stratospheric ozone depletion and its role in the recent increase of Antarctic sea ice extent. Geophys. Res. Lett., 36, L08502, doi:10.1029/2009GL037524.

Young, P., A. Butler, N. Calvo, L. Haimberger, P. Kushner, D. Marsh, W. J. Randel, and K. H. Rosenlof, 2013: Agreement in late twentieth century Southern Hemisphere stratospheric temperature trends in observations and CCMVal-2, CMIP3, and CMIP5 models. J. Geophys. Res. Atmos., 118, 605-613, doi:10.1002/jgrd.50126. 
Copyright of Journal of Climate is the property of American Meteorological Society and its content may not be copied or emailed to multiple sites or posted to a listserv without the copyright holder's express written permission. However, users may print, download, or email articles for individual use. 